\title{
1-Methyl-4-Phenylpyridinium Induces Autocrine Excitotoxicity, Protease Activation, and Neuronal Apoptosis
}

\author{
MARCEL LEIST, CHRISTIANE VOLBRACHT, EUGENIO FAVA, and PIERLUIGI NICOTERA \\ Faculty of Biology, Chair of Molecular Toxicology, University of Konstanz, D-78457 Konstanz, Germany
}

\begin{abstract}
The pathogenesis of several neurodegenerative diseases may involve indirect excitotoxic mechanisms, where glutamate receptor overstimulation is a secondary consequence of initial functional defects of neurons (e.g., impairment of mitochondrial energy generation). The neurotoxin 1-methyl-4-phenylpyridinium $\left(\mathrm{MPP}^{+}\right)$and other mitochondrial inhibitors (e.g., rotenone or 3-nitropropionic acid) elicited apoptosis in cerebellar granule cell cultures via stimulation of autocrine excitotoxicity. Cell death, increase in intracellular $\mathrm{Ca}^{2+}$ concentration, release of cytochrome $c$, and all biochemical and morphological signs of apoptosis were prevented by blockade of the $N$-methyl-Daspartate receptor with noncompetitive, glycine-site or glutamate-site inhibitors. In addition, $\mathrm{MPP}^{+}$-induced apoptosis was
\end{abstract}

reduced by high $\mathrm{Mg}^{2+}$ concentrations in the medium or by inhibiting exocytosis with clostridial neurotoxins. Two classes of cysteine proteases were involved in the execution of cell death: caspases and calpains. Inhibitors of either class of proteases prevented cell death, cleavage of intracellular proteins (i.e., fodrin), and the appearance of typical features of apoptosis such as phosphatidylserine translocation or DNA fragmentation. However, protease inhibitors did not interfere with the initial intracellular $\mathrm{Ca}^{2+}$ concentration increase. We suggest that $\mathrm{MPP}^{+}$as well as other mitochondrial inhibitors trigger indirect excitotoxic processes, which lead to $\mathrm{Ca}^{2+}$ overload, protease activation, and subsequent neuronal apoptosis.
Excitotoxic mechanisms (i.e., excessive stimulation of glutamate receptors with a resultant disturbance of cellular $\left[\mathrm{Ca}^{2+}\right]_{\mathrm{i}}$ homeostasis) may be involved in stroke and possibly in slowly developing neurodegenerative diseases (Choi and Rothman, 1990). However, glutamate receptor stimulation is rarely a primary event in neurotoxicity. Glutamate release and glutamate-triggered excitotoxicity are rather secondary consequences of other defects or metabolic disturbances. A frequent initiating condition is energy depletion, and mitochondrial dysfunction is among the most generalized causes favoring the development of different neurodegenerative diseases (Beal, 1996). For example, Huntington's disease is modeled by exposing specific neuronal subpopulations to mitochondrial toxins (Ferrante et al., 1997), and ischemic damage can be examined in vitro after mitochondrial substrate

This study was supported by the DFG Grants Ni519/1-1 and Ni519/2-1 and the EEC Grants ENV4-CT96-0169, BMH4CT97-2410, and 12029-97-06 F1ED ISP D. depletion due to oxygen/glucose deprivation (Choi and Rothman, 1990).

In these models, a close relationship has been established between energy deficiency and excitotoxicity. The ATP loss resulting from decreased mitochondrial energy generation would lead to impaired function of ion pumps and partial hypopolarization of neurons, thereby releasing the voltagedependent $\mathrm{Mg}^{2+}$ block of the NMDA-R-gated $\mathrm{Ca}^{2+}$ channel. This would make the receptor/channel hypersensitive to glutamate stimulation. NMDA-R-mediated influx of $\mathrm{Na}^{+}$and $\mathrm{Ca}^{2+}$ then would increase energy demand and ATP depletion, enhance depolarization, trigger further $\left[\mathrm{Ca}^{2+}\right]_{i}$ increase, and eventually result in further glutamate release. This putatively self-propagating process finally leading to a loss of $\left[\mathrm{Ca}^{2+}\right]_{\mathrm{i}}$ homeostasis and excitotoxicity has been termed the "energy-linked excitotoxicity hypothesis" (Henneberry et al., 1989; Zeevalk and Nicklas, 1990). Distal mechanisms (downstream of $\left[\mathrm{Ca}^{2+}\right]_{\mathrm{i}}$ increase) leading to neuronal death under such conditions may differ from those operating

ABBREVIATIONS: $\left[\mathrm{Ca}^{2+}\right]_{\mathrm{i}}$, intracellular $\mathrm{Ca}^{2+}$ concentration; $\Delta \Psi$, mitochondrial membrane potential; AP5, 5-aminophosphovalerat; calp II, acetyl-leucyl-leucyl-L-methional; calp III, z-Val-L-phenylalaninal; CCCP, carbonylcyanide-chlorophenylhydrazone; CGC, cerebellar granule cells; CSS, controlled salt solution; DCK, 5,7-dichlorokynurenate; DIV, days in vitro; EGTA, ethylene glycol bis $\left(\beta\right.$-aminoethyl ether)- $N, N, N^{\prime}, N^{\prime}$-tetraacetic acid; HEPES, 4-(2-hydroxyethyl)-1-piperazineethanesulfonic acid; DNQX, dinitroquinoxalinedione; MK801, (+)-5-methyl-10,11-dihydro-5H-dibenzo[a,d]cyclohepten-5,10-imine; MPP $^{+}$, 1-methyl-4-phenylpyridinium; MTT, 3-(4,5-dimethylthiazole-2-yl)-2,5-diphenyltetrasodium bromide; NMDA, N-methyl-D-aspartate; NMDA-R, N-methyl-D-aspartate receptor; NO, nitric oxide; 3-NP, 3-nitropropionic acid; PARP, poly-(ADP-ribose)polymerase (E.C. 2.4.2.30); BoNT/C, botulinum neurotoxin serotype C; PS, phosphatidylserine; TMRE, tetramethylrhodamine ethylester; VDCC, voltage-dependent calcium channel; z-D-cbk, z-aspartyl-2,6-dichlorobenzoyloxymethylketone. 
after simple glutamate receptor stimulation and are largely unknown.

Excitotoxicity may lead to either necrosis or to a more ordered sequence of molecular events resulting in apoptosis (Ankarcrona et al., 1995; Leist and Nicotera, 1998). Recent work in our laboratory has shown caspase activation downstream to the initial $\left[\mathrm{Ca}^{2+}\right]_{\mathrm{i}}$ increase in a model of indirect excitotoxicity, where NMDA-R activation was triggered by NO (Leist et al., 1997a, 1997d). In parallel, studies in vivo have suggested that caspases may be involved in neuronal damage after stroke (Loddick et al., 1996). In all these models, the exact primary insult is little characterized and possibly not limited to mitochondrial dysfunction; therefore, it is still unclear how a primary mitochondrial impairment can lead to excitotoxic apoptosis.

The neurotoxin MPTP induces a Parkinson's disease-like syndrome in humans and animals via its active metabolite, $\mathrm{MPP}^{+}$(Tipton and Singer, 1993). Although $\mathrm{MPP}^{+}$affects only certain neurons in vivo due to pharmacokinetic reason, the substance inhibits mitochondrial function in any cultured neuronal or non-neuronal cell or isolated mitochondria. A known molecular target of $\mathrm{MPP}^{+}$is the mitochondrial respiratory chain complex I (NADH-ubiquinone-oxidoreductase) (Nicklas et al., 1985; Kilbourn et al., 1997), and no other main target has been characterized to date, despite extensive studies. In vivo (i.e., in the presence of glutamatergic cortical inputs), the primary impairment of mitochondrial respiration by $\mathrm{MPP}^{+}$sensitizes neurons to secondary excitotoxic damage. Thus, blockade of glutamate receptors (Turski et al., 1991; Srivastava et al., 1993) or prevention of the synthesis of endogenous NO (Schulz et al., 1995; Hantraye et al., 1996), a mediator closely linked to excitotoxicity, has been found to reduce $\mathrm{MPP}^{+}$toxicity in animals.

In the current study, we exposed neurons to the mitochondrial poison $\mathrm{MPP}^{+}$or other respiratory chain inhibitors. CGC have been shown to be susceptible to $\mathrm{MPP}^{+}$(Marini et al., 1989). Thus, we used here neuronal cultures, which mimic the very high density of excitable glutamatergic synapses present in vivo. Densely plated CGC, differentiated for $\geq 8$ days in $\mathrm{K}^{+}$-supplemented medium, represent an ideal culture system for this purpose. We examined in this culture system (i) whether excitotoxic mechanisms contribute to $\mathrm{MPP}^{+}$toxicity, (ii) whether such excitotoxicity results in apoptosis, (iii) under which conditions the execution of excitotoxic death triggered by $\mathrm{MPP}^{+}$or other mitochondrial toxins involves caspases, and (iv) which apoptotic features depend on the activity of protease families activated by excitotoxic disruption of $\left[\mathrm{Ca}^{2+}\right]_{i}$ homeostasis.

\section{Experimental Procedures}

Materials. Fluo 3-acetoxymethyl ester, Fura 2-acetoxymethyl ester, calcein acetoxymethyl ester, TMRE, SYTOX, ethidium homodimer-1, and H-33342 were obtained from Molecular Probes (Eugene, OR). The caspase substrate DEVD-afc, $\mathrm{MPP}^{+}, \mathrm{DCK}, \mathrm{DNQX}$, and 6,7-dichloroquinoxaline-2,3-dione were obtained from BIOMOL (Hamburg, Germany). MK801 came from RBI (Biotrend Chemikalien GmbH, Köln, Germany). succ-LLVY-amc; calpain inhibitors I, II, and III (Ac-Leu-Leu-L-norleucinal, Ac-Leu-Leu-L-methional, and calp III, z-Phe-chloromethylketone ( $\mathrm{cmk}$ ); and the caspase-inhibitors DEVD-CHO, z-VAD-fluoromethylketone (fmk), Ac-YVAD-cmk, or Ac-YVAD-2,6-dimethylbenzoyloxymethylketone (ICE II) and z-D2,6-dichlorobenzoyloxymethylketone (cbk) (ICE III) were obtained from Bachem Biochemica (Heidelberg, Germany). DEVD-fmk was from Enzyme Systems (Dublin, CA). Fluorescein-labeled annexin V (annexin V) was from Boehringer-Mannheim (Mannheim, Germany). Clostridial toxins were generously supplied by Dr. C. Montecucco (University of Padova, Padova, Italy). Solvents and inorganic salts were from Merck (Darmstadt, Germany) or Riedel-de Haen (Seelze, Germany). All other reagents not further specified were from Sigma (Deisenhofen, Germany).

Animals. $\mathrm{PARP}^{-1-}$ mice $(\mathrm{C} 57 \mathrm{Bl} / 6 \times 129 / \mathrm{Sv}$ background $)$ or corresponding wild-type animals were generously provided by Dr. Zhao-Qi Wang (IARC, Lyon, France) (Wang et al., 1995). All animals used for cell preparations were typed by Southern blotting (Wang et $a l ., 1995)$ to verify the genotype. For other experiments, 8-day-old specific pathogen-free BALB/c mice were obtained from the Animal Unit of the University of Konstanz. All experiments were performed in accordance with international guidelines to minimize pain and discomfort (National Institutes of Health guidelines and European Community Council Directive 86/609/EEC).

Cell culture. Murine CGC were prepared as described previously (Schousboe et al., 1989). Neurons were plated onto $100 \mu \mathrm{g} / \mathrm{ml}(250$ $\mu \mathrm{g} / \mathrm{ml}$ for glass surfaces) poly-L-lysine (molecular mass, $>300 \mathrm{kDa}$ )coated dishes at a density of $\sim 0.25 \times 10^{6} \mathrm{cells} / \mathrm{cm}^{2}(800,000 \mathrm{cell} / \mathrm{s} / \mathrm{ml}$; $500 \mu \mathrm{l} /$ well; 24-well plate) and cultured in Eagle's basal medium (GIBCO, Paisley, Scotland) supplemented with $10 \%$ heat-inactivated fetal calf serum, $20 \mathrm{~mm} \mathrm{KCl,} 2 \mathrm{~mm}$ L-glutamine, 100 units/ml penicillin, and $100 \mu \mathrm{g} / \mathrm{ml}$ streptomycin. Forty-eight hours after plating, cytosine arabinoside $(10 \mu \mathrm{M})$ was added to the cultures. Neurons were routinely used at 8-10 DIV unless otherwise indicated. Glial fibrillary acid protein-positive cells were $<5 \%$.

Cytotoxicity assays. Cultures were exposed to $\mathrm{MPP}^{+}$or rotenone in their own medium. The culture medium was exchanged for a CSS (120 mm NaCl, $25 \mathrm{~mm}$ HEPES, $25 \mathrm{~mm} \mathrm{KCl,} 1.8 \mathrm{~mm} \mathrm{CaCl}_{2}, 4 \mathrm{~mm}$ $\mathrm{MgCl}_{2}$ ) plus $15 \mathrm{~mm}$ glucose $4 \mathrm{hr}$ after the start of the incubation, and the cells were left in this medium until toxicity parameters were read (usually $18 \mathrm{hr}$ for MTT or nuclear morphology). Inhibitors were added routinely $30 \mathrm{~min}$ before exposure to $\mathrm{MPP}^{+}$.

To assess plasma membrane integrity and nuclear morphology, CGC were loaded with $0.5 \mu \mathrm{M}$ calcein acetoxymethyl ester for $5 \mathrm{~min}$ (cells with intact membranes display green fluorescence) in the presence of $1 \mu \mathrm{M}$ ethidium homodimer-1 (cells with broken membranes exhibit nuclear red fluorescence) and $500 \mathrm{ng} / \mathrm{ml}$ concentration of the bisbenzimide dye H-33342 (cell permeant, blue-fluorescent). Alternatively, apoptosis and secondary lysis were quantified by double staining neuronal cultures with $1 \mu \mathrm{g} / \mathrm{ml} \mathrm{H}-33342$ and $0.5 \mu \mathrm{M}$ SYTOX (non-cell-permeant, green-fluorescent chromatin stain). Apoptotic cells were characterized by condensed highly fluorescent nuclei. About 600-1000 cells were counted in nine different fields in two or three different culture wells, and experiments were repeated in at least three different preparations. In addition, the percentage of viable cells was quantified by their MTT-reducing capacity after incubation with $0.5 \mathrm{mg} / \mathrm{ml}$ MTT for $60 \mathrm{~min}$. The viability of untreated control cultures was set to $100 \%$, and the viability of treated cultures was expressed as percentage of formazan absorbance compared with that of control cultures.

$\mathbf{C a}^{2+}$ measurements. The $\left[\mathrm{Ca}^{2+}\right]_{\mathrm{i}}$ was measured by imaging neurons loaded with fluorescent $\mathrm{Ca}^{2+}$ indicators. To monitor dynamic changes of $\mathrm{Ca}^{2+}$, CGC were loaded in their original medium with $1 \mu \mathrm{M}$ fluo-3 acetoxymethyl ester for $10 \mathrm{~min}$ at $37^{\circ}$. The medium then was exchanged for CSS, in which CGC were incubated for $5 \mathrm{~min}$ to allow complete de-esterification of fluo-3. The medium was exchanged again for the original neuron-conditioned complete Eagle's basal medium supplemented with $20 \mathrm{~mm}$ HEPES $\left(\mathrm{MPP}^{+}\right.$as stimulus) or for CSS (without $\mathrm{Mg}^{2+}$ ) (50 $\mu \mathrm{M}$ glutamate or $200 \mu \mathrm{M}$ NMDA as stimulus) or for CSS plus $2 \mu \mathrm{M}$ MK801 (200 $\mu \mathrm{M}$ kainate as stimulus). CGC were allowed to equilibrate at room temperature for $10 \mathrm{~min}$ before the exposure. Images were collected using the 488-nm excitation and 520-nm emission wavelengths and a Leica DM-IRB microscope equipped with a $40 \times$ NA 1.0 lens. Data from 10-20 neurons 
were recorded at 3-60-sec intervals with a Leica TCS $4 \mathrm{D}$ confocal system. Relative mean fluorescence levels from defined areas corresponding to the position of neuronal cell bodies were recorded over the time course of the experiment, and the values were arbitrarily set to 1 at the beginning of each experiment. To determine absolute $\left[\mathrm{Ca}^{2+}\right]_{\mathrm{i}}$, we used the low $K_{d}$ indicator Fura 2-acetoxymethyl ester $(2.5$ $\mu \mathrm{M}$; Molecular Probes, Eugene, OR), which reports $\left[\mathrm{Ca}^{2+}\right]_{i}$ exactly in the low concentration range $(\leq 500 \mathrm{nM})$. This allowed us to examine whether MK801 would maintain $\left[\mathrm{Ca}^{2+}\right]_{\mathrm{i}}$ to base-line levels in $\mathrm{MPP}^{+}$treated cells. A Leica M-IRB microscope equipped with a computercontrolled filter wheel (Sutter, Novato, CA), quartz optics, and a Dage-72 (Dage-MTI; Michigan City, IN) charge-coupled device $(\mathrm{CCD})$ camera $[756(\mathrm{H}) \times 581(\mathrm{~V})$ pixels] coupled to a videoscope GEN-III image intensifier was used for imaging $\left(\lambda_{\text {ex-1 }}=340 \mathrm{~nm}, \lambda_{\text {ex-2 }}\right.$ $\left.=380 \mathrm{~nm}, \lambda_{\mathrm{em}}=505 \mathrm{~nm}\right)$. Videomicroscopy data were analyzed using software from Imaging Research (St. Catherine's, Ontario, Canada). $\left[\mathrm{Ca}^{2+}\right]_{\mathrm{i}}$ was determined by in situ calibration using the equation $\left[\mathrm{Ca}^{2+}\right]_{\mathrm{i}}=K_{d} \times\left(R-R_{\min }\right) /\left(R_{\max }-R\right) \times \mathrm{S}_{\mathrm{f} 2} / \mathrm{S}_{\mathrm{b} 2}$, with $K_{d\left(25^{\circ}\right)}$ $=264$ nM. To determine $R_{\text {min }}$, cells were washed twice with calibration buffer ( $120 \mathrm{~mm} \mathrm{NaCl}, 25 \mathrm{~mm}$ HEPES, $15 \mathrm{~mm}$ glucose, $25 \mathrm{~mm} \mathrm{KCl}$, $2 \mathrm{mM} \mathrm{MgCl}_{2}, 2 \mathrm{~mm}$ EGTA) and equilibrated for $20 \mathrm{~min}$ in calibration buffer supplemented with $5 \mu \mathrm{M}$ ionomycin. $\mathrm{Ca}^{2+}(5 \mathrm{mM})$ and ionomycin $(10 \mu \mathrm{M})$ were added to saturate Fura- 2 with $\mathrm{Ca}^{2+}$ and calculate $R_{\max }$. Autofluorescence was measured after the addition of $5 \mathrm{~mm}$ $\mathrm{MnCl}_{2}$.

Electrophoretic assays. Fodrin proteolysis was analyzed by immunoblot. CGC cultures were lysed in RIPA buffer ( $150 \mathrm{~mm} \mathrm{NaCl}, 50$ mu Tris, $1 \%$ Nonidet P-40, $0.25 \%$ sodium deoxycholate, 1 mm EGTA) supplemented with protease inhibitors (1 mM phenylmethylsulfonyl fluoride, $1 \mathrm{~mm}$ benzamidine, $1 \mathrm{~mm}$ iodoacetate, $1 \mathrm{~mm}$ iodoacetamide, $40 \mu \mathrm{m}$ leupeptin, $10 \mu \mathrm{g} / \mathrm{ml}$ antipain, $5 \mu \mathrm{g} / \mathrm{ml}$ pepstatin). Before lysis, cultures were stained with $0.5 \mu \mathrm{M}$ SYTOX to control the percentage of cells with intact membranes, which was $>95 \%$ for all samples analyzed. Protein was determined using the bicinchoninic acid method (BioRad, München, Germany), and $5 \mu \mathrm{g}$ of protein/lane was loaded onto $8 \%$ polyacrylamide gels. Proteins were separated under reducing conditions at $60 \mathrm{~mA}$ and then blotted onot a nitrocellulose membrane (Amersham-Buchler, Braunschweig, Germany) in a BioRad semidry blotter at $2.6 \mathrm{~mA} / \mathrm{cm}^{2}$ for 50 min using a Towbin buffer system. Blots were blocked for $1 \mathrm{hr}$ and then incubated with antifodrin monoclonal antibody (clone 1622, 1:1000) from Chemicon (Temecula, CA) diluted in TNT (150 mM NaCl, $50 \mathrm{~mm}$ Tris, $\mathrm{pH} 8.0$, $0.05 \%$ Tween 20 ) for $1 \mathrm{hr}$ at room temperature. Specifically stained bands were detected by enhanced chemiluminescence (Amersham) using a peroxidase-coupled secondary antibody. For Western blot analysis of procaspase-3 (14\% gel, $60 \mu \mathrm{g}$ of neuronal protein/lane), we used a primary rabbit anti-human procaspase-3 polyclonal antibody (1:1000, no. 06753; Upstate Biotechnology, Lake Placid, NY) recognizing the $32-\mathrm{kDa}$ murine procaspase but not the cleavage products.

Field inversion gel electrophoresis was performed as described previously (Ankarcrona et al., 1995; Leist et al., 1997d). About $5 \times$ $10^{6}$ cells (corresponding to 3 wells of a 12 -well plate) were embedded into $40-\mu \mathrm{l}$ agarose blocks. $\lambda$-DNA concatemers $(n \times 50 \mathrm{kbp})$ were used as molecular weight markers.

Mitochondrial function and integrity. ATP was measured luminometrically after lysis of cells in ATP-releasing agent (Sigma) with a commercial kit (Boehringer-Mannheim) as described previously (Leist et al., 1997c). The $\Delta \Psi$ was monitored by loading cells with the fluorescent indicator TMRE ( $5 \mathrm{nM:} \lambda_{\mathrm{ex}}, 568 \mathrm{~nm} ; \lambda_{\mathrm{em}}, \geq 590$ $\mathrm{nm})$. Under these conditions, fluorescence completely disappeared on loss of $\Delta \Psi(50 \mu \mathrm{M}$ glutamate or $50 \mu \mathrm{M}$ CCCP) in neurons that retained plasma membrane integrity. For the experiments, at least three culture dishes were imaged in at least six cell preparations for each data point presented. For semiquantitative analysis of $\Delta \Psi$, we added red fluorescent beads of $2-\mu \mathrm{m}$ diameter and calibrated fluorescence intensity (Molecular Probes, Eugene, OR) to the cultures. The standardized fluorescence of the beads was used as an internal standard to normalize the fluorescence intensities of digitized im- ages of TMRE-loaded neurons. The fluorescence of neurons treated with $20 \mu \mathrm{M}$ CCCP was used as reference for depolarized mitochondria.

The release of cytochrome $c$ from mitochondria was analyzed by a selective digitonin permeabilization method. This protocol was established to avoid possible artifacts due to potential mechanical breakage of the outer mitochondrial membrane of apoptotic cells by Dounce homogenization. At the indicated time points, the culture medium was exchanged for permeabilization buffer (210 mM D-mannitol, $70 \mathrm{~mm}$ sucrose, $10 \mathrm{~mm}$ HEPES, $5 \mathrm{~mm}$ succinate, $0.2 \mathrm{~mm}$ EGTA, $0.15 \% \mathrm{BSA}, 80 \mu \mathrm{g} / \mathrm{ml}$ digitonin, $\mathrm{pH} 7.2,4^{\circ}$ ). Cell culture plates were shaken gently for $5 \mathrm{~min}$ at $4^{\circ}$, and then the permeabilization buffer was removed and centrifuged for $10 \mathrm{~min}$ at $13,000 \times \mathrm{g}$. Protein from the supernatants of this centrifugation was precipitated with $5 \%$ trichloroacetic acid and separated on a $15 \%$ polyacrylamide gel. All samples were obtained from supernatants derived from $10^{6}$ CGC. Cytochrome $c$ was detected by chemiluminescent detection after blotting on nitrocellulose membranes with a monoclonal antibody raised against pigeon cytochrome $c$ (clone 7H8.2C12; Pharmingen, San Diego, CA). At the digitonin concentration used in these experiments, neurons released LDH and became permeable to the fluorescent chromatin dye SYTOX or propidium iodide. Control experiments showed that cytochrome $c$ was not released into the supernatant of untreated cultures even after 20-min incubation in the permeabilization buffer. Treatment of these cultures with Triton $\mathrm{X}-100$ led to a maximal release of cytochrome $c$ into the supernatant. As an additional control, we stained cytochrome $c$ in situ, using a monoclonal antibody directed against native cytochrome $c$ (clone 6H2.B4). In control neurons treated for $10 \mathrm{~min}$ with permeabilization buffer and then fixed with paraformaldehyde, punctate cytochrome $c$ staining colocalized entirely with a fixable mitochondrial marker (CMX-rosamine, Mito-Tracker Red; Molecular Probes, Eugene, OR), and the stain intensity was identical to that of untreated cells (i.e., without the addition of permeabilization buffer) stained and fixed in the same way.

Enzymatic assays. Caspase-3-like activity (measured by DEVDafc cleavage) was assayed as described previously (Leist et al., 1997b) with the following modifications: CGC were pelleted in PBS supplemented with $5 \mathrm{~mm}$ EDTA, $1 \mu \mathrm{g} / \mathrm{ml}$ leupeptin, $1 \mu \mathrm{g} / \mathrm{ml}$ pepstatin, 1 $\mu \mathrm{g} / \mathrm{ml}$ aprotinin, and $1 \mathrm{~mm}$ PEFA-block. Lysis was performed in 25 mM HEPES, 5 mM $\mathrm{MgCl}_{2}, 1 \mathrm{~mm}$ EGTA, 0.5\% Triton X-100, $1 \mu \mathrm{g} / \mathrm{ml}$ leupeptin, $1 \mu \mathrm{g} / \mathrm{ml}$ pepstatin, $1 \mu \mathrm{g} / \mathrm{ml}$ aprotinin, and $1 \mathrm{~mm}$ PEFA-

\section{TABLE 1}

Modulation of mitochondrial function and apoptosis by respiratory chain inhibitors

\begin{tabular}{|c|c|c|c|}
\hline Treatment $^{a}$ & $\Delta \Psi^{b}$ & $\mathrm{ATP}^{c}$ & Apoptosis $^{d}$ \\
\hline & & $\%$ & $\%$ \\
\hline $\mathrm{MPP}^{+}$ & - & 2.0 & $>80$ \\
\hline $\mathrm{MPP}^{+}+\mathrm{MK} 801$ & ++ & 5.8 & $<10$ \\
\hline $3-\mathrm{NP}$ & - & 9.1 & $>80$ \\
\hline $3-\mathrm{NP}+\mathrm{MK} 801$ & ++ & 18.5 & $<10$ \\
\hline $\mathrm{DG}$ & + & 9.6 & $<10$ \\
\hline $\mathrm{DG}+$ pyruvate & ++ & 45.0 & $<10$ \\
\hline $\mathrm{MPP}^{+}+\mathrm{DG}$ & - & 1.3 & $>80$ \\
\hline $\mathrm{MPP}^{+}+\mathrm{DG}+\mathrm{MK} 801$ & - & 1.8 & $<10$ \\
\hline $3-\mathrm{NP}+\mathrm{DG}$ & - & 1.4 & $>80$ \\
\hline 3-NP + DG + MK801 & - & 9.9 & $<10$ \\
\hline $\mathrm{MPP}^{+}+$methylsuccinate & + & 3.7 & $<10$ \\
\hline DG (40 mm) & N.D. & 3.3 & $>80$ \\
\hline $\mathrm{DG}(40 \mathrm{~mm})+\mathrm{MK} 801$ & N.D. & 5.6 & $<10$ \\
\hline
\end{tabular}

${ }^{a}$ Neurons were exposed to combinations of $\mathrm{MPP}^{+}(50 \mu \mathrm{M}), \mathrm{DG}(20 \mathrm{~mm}), 3-\mathrm{NP}(400$ $\mu \mathrm{M})$, methylsuccinate $(5 \mathrm{~mm})$, pyruvate $(4 \mathrm{~mm})$, or MK801 $(2 \mu \mathrm{M})$ for $3 \mathrm{hr}$ in the original culture medium.

${ }^{b} \Delta \Psi$ was measured in cells loaded with $5 \mathrm{~nm}$ TMRE. Fluorescence intensity corresponding to $70-100 \%$ of controls is indicated by,$++ 30-70 \%$ by + , and $<30 \%$ by - .

${ }^{c}$ ATP is given as percentage of control cells. Data are mean values from three different cell preparations. Standard deviations were always below $3 \%$.

${ }^{d}$ Apoptosis was determined by counting the percentage of condensed nuclei after staining with $\mathrm{H}-33342$. 
block, $\mathrm{pH}$ 7.5. The fluorimetric assay was carried out in microtiter plates with a substrate concentration of $40 \mu \mathrm{M}$ and a total protein amount of $5 \mu \mathrm{g}$. Cleavage of DEVD-afc was followed in reaction buffer (50 mM HEPES, $10 \mathrm{~mm}$ dithiothreitol, 1\% sucrose, 0.1\% 3-[(3cholamidopropyl)dimethylammonio]propanesulfonate) over a period of $30 \mathrm{~min}$ at $37^{\circ}$ with $\lambda_{\mathrm{ex}}=390 \mathrm{~nm}$ and $\lambda_{\mathrm{em}}=505 \mathrm{~nm}$, and the activity was calibrated with afc-standard solutions. Calpain activity was determined by a kinetic fluorimetric assay as described previously (Leist et al., 1997d). Glucose concentrations in the medium were determined according to the hexokinase/glucose dehydrogenase method using a commercial kit (Sigma).

Visualization of PS translocation. Cells stained with different fluorescent probes were imaged on a Leica DM-IRBE microscope equipped with a computer-controlled $\mathrm{z}$-stage and connected to a TCS-4D UV/VIS confocal scanning system (Leica AG, Benzheim, and Leica Lasertechnik, Heidelberg, Germany). The staining protocol for fluorescein-conjugated annexin V (detection of PS on the outer leaflet of the plasma membrane) was adapted for neuronal cultures as follows: CGC were grown on glass-bottomed culture dishes and incubated with $\mathrm{MPP}^{+}$or rotenone with or without inhibitors. At the end of the incubation periods, $0.5 \mu \mathrm{g} / \mathrm{ml} \mathrm{H}-33342$ was added to the cultures to later visualize chromatin structure. After a 10-min incubation at $37^{\circ}, \mathrm{CGC}$ were washed for $10 \mathrm{sec}$ with binding buffer (10 mM HEPES, $140 \mathrm{~mm} \mathrm{NaCl}, 2.5 \mathrm{~mm} \mathrm{CaCl}_{2}, 10 \mathrm{~mm} \mathrm{MgCl}_{2}$ ) and subsequently incubated for $2 \mathrm{~min}$ in the dark with annexin $\mathrm{V}$ diluted 1:100 in binding buffer. After a new wash with binding buffer, stained cultures were immersed in binding buffer supplemented with $0.25 \mu \mathrm{M}$ ethidium homodimer- 1 and visualized by three-channel confocal microscopy (blue, chromatin structure, green, annexin binding, red, membrane integrity) using a $63 \times / \mathrm{NA} 1.32$ UV-corrected lens.

Statistics. Toxicity experiments were run in triplicate and repeated in three to eight cell preparations. Statistical significance was calculated on the original data sets using the Student's $t$ test. When variances within the compared groups were not homogeneous, the Welch test was applied. Western blots and measurements of $\left[\mathrm{Ca}^{2+}\right]_{\mathrm{i}}$ were repeated in at least three independent cell preparations.

\section{Results}

A role for the NMDA-R in $\mathrm{MPP}^{+}$-induced CGC apoptosis. $\mathrm{MPP}^{+}$caused apoptosis of differentiated (8 DIV) CGC in a concentration range of $25-100 \mu \mathrm{M}$ (Fig. 1). Toxicity of $\mathrm{MPP}^{+}$was evident in cells exposed to $\mathrm{MPP}^{+}$for $2-4 \mathrm{hr}$, unlike the slow toxicity observed in an earlier report (Marini et al., 1989). Susceptibility of CGC to such rapidly developing

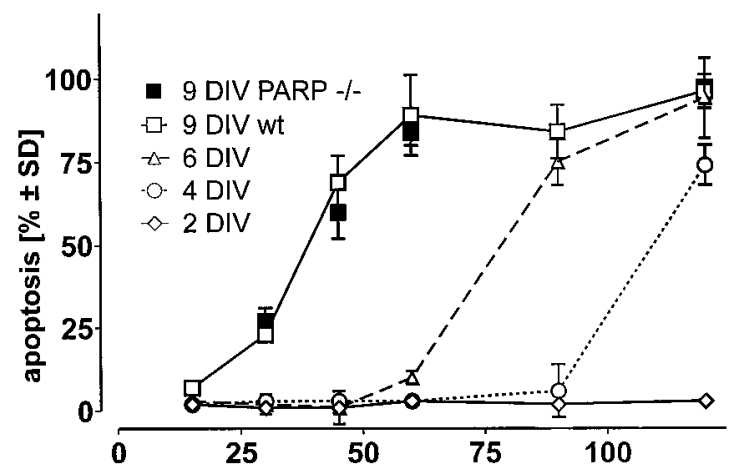

Fig. 1. $\mathrm{MPP}^{+}$-induced apoptosis in CGC cultures from wild-type and $\mathrm{PARP}^{-1-}$ animals. Cultures from wild-type CGC of different culture age $(w t)$ or PARP-deficient mice $\left(P A R P^{-{ }^{-}}\right)$were challenged with $\mathrm{MPP}^{+}$ concentrations as indicated. The percentage of neurons with apoptotic nuclei was determined after $7 \mathrm{hr}$ by staining with fluorescent chromatin dyes and counting of the cells. Data are mean \pm standard deviation of triplicate determinations.
$\mathrm{MPP}^{+}$-induced apoptosis was strongly dependent on the cell differentiation state. CGC were hardly sensitive toward $\mathrm{MPP}^{+}$during the first $2 \mathrm{DIV}$, whereas they became progressively more susceptible to induction of apoptosis elicited by $\mathrm{MPP}^{+}$with increasing time in culture, as described elsewhere for other excitotoxic stimuli (i.e., NMDA, NO, or $\mathrm{ONOO}^{-}$) (Leist et al., 1997a) (Fig. 1).

The rapid toxicity of $\mathrm{MPP}^{+}$(4-hr exposure) was entirely prevented by the noncompetitive NMDA-R blocker MK801 over the full concentration range used in this study $\left(\mathrm{MPP}^{+} \leq\right.$ $120 \mu \mathrm{M}$ ) (Fig. 2A). In the presence of $\mathrm{MK}^{2} 01, \mathrm{MPP}^{+}$also caused no significant cell death when neurons were continuously exposed for $18 \mathrm{hr}$. Long preincubation with MK801 was not required because the channel blocker still protected $\mathrm{MPP}^{+}$-challenged neurons when it was added up to $15 \mathrm{~min}$ after the exposure to $\mathrm{MPP}^{+}$. Neurons challenged for $4 \mathrm{hr}$ with $50 \mu \mathrm{M} \mathrm{MPP}{ }^{+}$in the presence of MK801 and then cultured in conditioned medium without $\mathrm{MPP}^{+}$for an additional $96 \mathrm{hr}$ were virtually unaffected ( $\geq 95 \%$ viable). In contrast, CGC exposed permanently to $\mathrm{MPP}^{+}$at concentrations of $\geq 50$ $\mu \mathrm{M}$, in the presence of MK801, showed signs of degeneration after $24 \mathrm{hr}$ and died after $36-72 \mathrm{hr}$. This suggests that chronic exposure of CGC to $\mathrm{MPP}^{+}$resulted in the activation of additional, nonexcitotoxicity mechanisms.
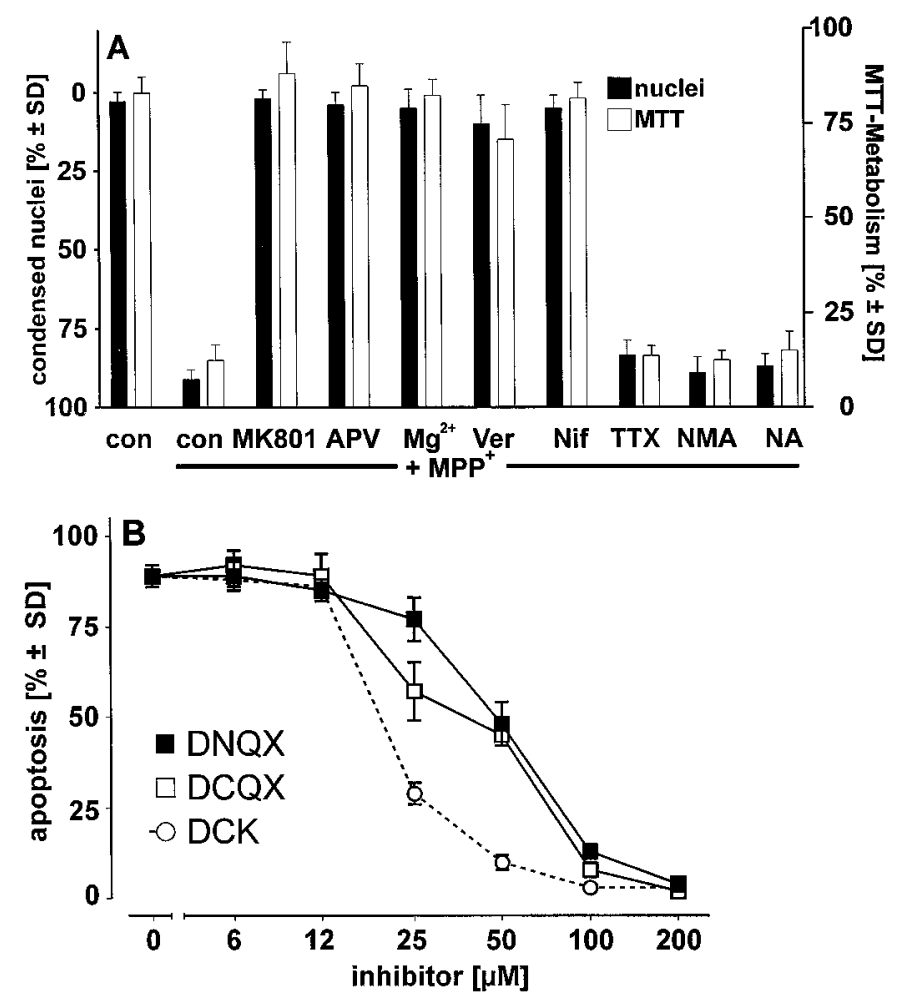

Fig. 2. Prevention of $\mathrm{MPP}^{+}$-induced CGC apoptosis by blockade of $\mathrm{Ca}^{2+}$ channels. Top, CGC were preincubated for $30 \mathrm{~min}$ with solvent $(0.4 \%$ DMSO; con) or $2 \mu \mathrm{M}$ MK801, $500 \mu \mathrm{M}$ AP5, $5 \mathrm{mM} \mathrm{Mg}^{2+}, 1 \mu \mathrm{M}$ verapamil (Ver), $1 \mu \mathrm{M}$ nifedipine (Nif), $500 \mathrm{~nm}$ tetrodotoxin (TTX), $400 \mu \mathrm{M} N$-methylL-arginine $(N M A)$, or $1 \mathrm{~mm}$ nitroarginine $(N A)$ before they were challenged with $50 \mu \mathrm{M} \mathrm{MPP}{ }^{+}$. Medium was exchanged for CSS after $4 \mathrm{hr}$, and cell death parameters were determined after $18 \mathrm{hr}$. Apoptosis was quantified by scoring condensed neuronal nuclei (note inverted scale); mitochondrial function was determined by measuring MTT-reduction capacity. Bottom, CGC were incubated as described above with different concentrations of inhibitors of the NMDA-R glycine site (DNQX, 6,7dichloroquinoxaline-2,3-dione, or DCK) plus $50 \mu \mathrm{M} \mathrm{MPP}^{+}$. Apoptosis was quantified after $18 \mathrm{hr}$. Data are mean \pm standard deviation of triplicate determinations. 
Other NMDA-R antagonists such as AP5, a competitive inhibitor of the glutamate binding site, or high $\mathrm{Mg}^{2+}$ concentrations in the medium protected $\mathrm{MPP}^{+}$-treated neurons (Fig. 2A). In addition, inhibitors acting on the costimulatory glycine-binding site of the NMDA-R prevented $\mathrm{MPP}^{+}$toxicity (Fig. 2B). The quinoxalinedione compounds used in this study (DNQX and CNQX) inhibit non-NMDA glutamate receptors at low concentrations $(\sim 20 \mu \mathrm{M})$ and block NMDA-R action at three or four times higher concentrations. Prevention of $\mathrm{MPP}^{+}$toxicity by these substances at concentrations of $\geq 50 \mu \mathrm{M}$ points to the predominant role of the NMDAactivated subtype of glutamate receptors for this effect. DCK, the most selective inhibitor of the NMDA-R glycine site tested here, also was most potent in inhibiting $\mathrm{MPP}^{+}$-induced CGC apoptosis. This further suggests a role for the NMDA-R and excitotoxicity in $\mathrm{MPP}^{+}$-induced CGC apoptosis.

Activation of VDCC has been shown to contribute significantly to NMDA-triggered neuronal $\left[\mathrm{Ca}^{2+}\right]_{\mathrm{i}}$ increase (reviewed in Leist and Nicotera, 1997). Therefore, we tested whether pharmacological inhibitors of VDCC had a further modulatory effect on $\mathrm{MPP}^{+}$toxicity. At intermediate $\mathrm{MPP}^{+}$ concentrations $(50 \mu \mathrm{M})$ and limited exposure times, protection of CGC was observed with either the dihydropyridinetype VDCC blocker nifedipine or with verapamil (Fig. 2A). At $\mathrm{MPP}^{+}$concentrations of $>50 \mu \mathrm{M}$, or when exposure was prolonged for $>4 \mathrm{hr}$, block of VDCC was not sufficient to prevent cell death.

It has been described previously that indirect excitotoxic damage in hippocampal cultures triggered by $\mathrm{Mg}^{2+}$ withdrawal and NMDA-R hypersensitization was blocked by the $\mathrm{Na}^{+}$channel blocker tetrodotoxin (Abele et al., 1990). We therefore examined whether activation of $\mathrm{Na}^{+}$channels, which may propagate membrane depolarization, was necessary for $\mathrm{MPP}^{+}$toxicity. In the case of indirect excitotoxicity triggered by $\mathrm{MPP}^{+}$in CGC, tetrodotoxin had no protective effect (Fig. 2A). This is in line with findings that KCl-triggered indirect excitotoxicity in cortical neuronal cultures (Monyer et al., 1992) or glutamate-dependent retinal damage due to inhibitors of energy metabolism (Zeevalk and Nicklas, 1991) is not significantly reduced by tetrodotoxin and thus also does not require the long-distance traveling of action potentials.

Rapid ATP depletion as a possible trigger of $\mathrm{MPP}^{+}$ excitotoxicity. Because energy depletion is known to trigger excitotoxic processes in different experimental systems, we examined intracellular ATP levels after treatment of CGC with $\mathrm{MPP}^{+}$. ATP declined slowly during the first $30 \mathrm{~min}$ of treatment with $\mathrm{MPP}^{+}$, and it was dissipated $\geq 90 \%$ after 3-4 hr. Treatment with MK801 delayed the loss of ATP by 30-60 min; however, at 3-4 hr after exposure to $\mathrm{MPP}^{+}, \mathrm{ATP}$ also was depleted in these cells (Fig. 3A). These findings suggest that $\mathrm{MPP}^{+}$caused a primary ATP depletion that was largely independent of the secondary excitotoxicity. This also implied that ATP depletion alone was not immediately lethal to neurons but rather sensitized them to glutamate and facilitated glutamate release. Under our culture conditions (residual glucose concentrations of $\sim 1 \mathrm{~mm}$ in the medium), glycolytic ATP production alone was not sufficient to maintain intracellular ATP concentrations at control levels after exposure to $\mathrm{MPP}^{+}$. Accordingly, the addition of $10 \mathrm{~mm}$ glucose delayed $\mathrm{MPP}^{+}$toxicity, which suggests that glycolysis re- mained functional. Also, when we measured the glucose consumption of neurons, the basal rate of $20 \mathrm{nmol} / 10^{6}$ cells $/ \mathrm{hr}$ increased to $\sim 400 \mathrm{nmol} / 10^{6}$ cells $/ 4 \mathrm{hr}$ in the presence of $\mathrm{MPP}^{+}$, regardless of whether MK801 was included in the culture dish.

Prevention of mitochondrial damage by NMDA-R block. In this system, $\mathrm{MPP}^{+}$may damage mitochondria by two ways: (i) by direct radical-induced damage and (ii) by triggering excitotoxicity, which results in $\mathrm{Ca}^{2+}$ overload and subsequent mitochondrial failure. We distinguished between these two mechanisms by comparing $\mathrm{MPP}^{+}$-triggered mitochondrial effects in the presence and absence of NMDA-R blockers. First, changes in $\Delta \Psi$ were examined by staining CGC with the mitochondrial potential-sensitive dye TMRE (Fig. 3B). CGC pretreated with MK801 (Fig. 3B) or AP5 (not shown) and then exposed to $\mathrm{MPP}^{+}$showed no significant loss of $\Delta \Psi$. In neurons exposed to $\mathrm{MPP}^{+}$alone, ATP depletion was paralleled by a complete loss of $\Delta \Psi$, in analogy with a model of direct excitotoxicity (Ankarcrona et al., 1995). Thus, loss of $\Delta \Psi$ seemed to be due to indirect excitotoxicity and preceded nuclear condensation and loss of membrane integrity. $\mathrm{MPP}^{+}$induced loss of TMRE fluorescence was selective for neurons because astrocytes within the same culture dish lost neither TMRE fluorescence nor viability. To confirm this finding, $\Delta \Psi$ also was monitored with the indicators JC-1 (Ankarcrona et al., 1995) and Mito-Tracker Red (CMX-rosamine). All dyes yielded similar results, but TMRE was most convenient for routine measurements because it was less photolabile than JC-1 and more suitable for monitoring long time periods (24 hr) than CMX-Ros, which reacts with cellular thiols.

To determine mitochondrial outer membrane integrity, we measured release of cytochrome $c$ from mitochondria into the cytosol. Treatment of CGC with $\mathrm{MPP}^{+}$caused cytochrome $c$ release within $90 \mathrm{~min}$ (Fig. 3C). Such mitochondrial damage was downstream to NMDA-R activation because it was entirely prevented by pretreatment of cells with MK801.

NMDA-R block inhibits loss of mitochondrial membrane potential and toxicity triggered by classic mitochondrial inhibitors. In view of these findings, we considered that NMDA-R-dependent toxicity might be triggered by other compounds affecting mitochondria. To evaluate this possibility, we exposed CGC to low concentrations of mitochondrial poisons such as oligomycin, CCCP, or rotenone. The latter blocks the respiratory chain at a site similar to that affected by $\mathrm{MPP}^{+}$(Kilbourn et al., 1997). Toxicity of oligomycin, CCCP, or rotenone was significantly ( $\geq 50 \%$ in all cases) reduced/delayed by MK801 (not shown). Pretreatment with MK801 completely prevented the toxicity of low concentrations of rotenone $(25-50 \mathrm{nM})$ and maintained $\Delta \Psi$ in short term incubation (Fig. 3D).

Similarly, we found that apoptosis induced by low concentrations of the complex II inhibitor 3-NP or by high concentrations of DG was completely prevented by MK801 (Table 1). 3-NP also stimulated glucose consumption similarly to $\mathrm{MPP}^{+}$ in the presence or absence of MK801 (not shown). Moreover, all mitochondrial inhibitors caused a marked ATP depletion, regardless of the presence or absence of MK801. Notably, in all cases, $\Delta \Psi$ was maintained long after the ATP depletion. Residual cytosolic ATP or alternative energy substrates likely contributed to the maintenance of $\Delta \Psi$. This is suggested by the finding that $\Delta \Psi$ was dissipated when mitochondrial inhibitors were added together with deoxyglucose. Nev- 

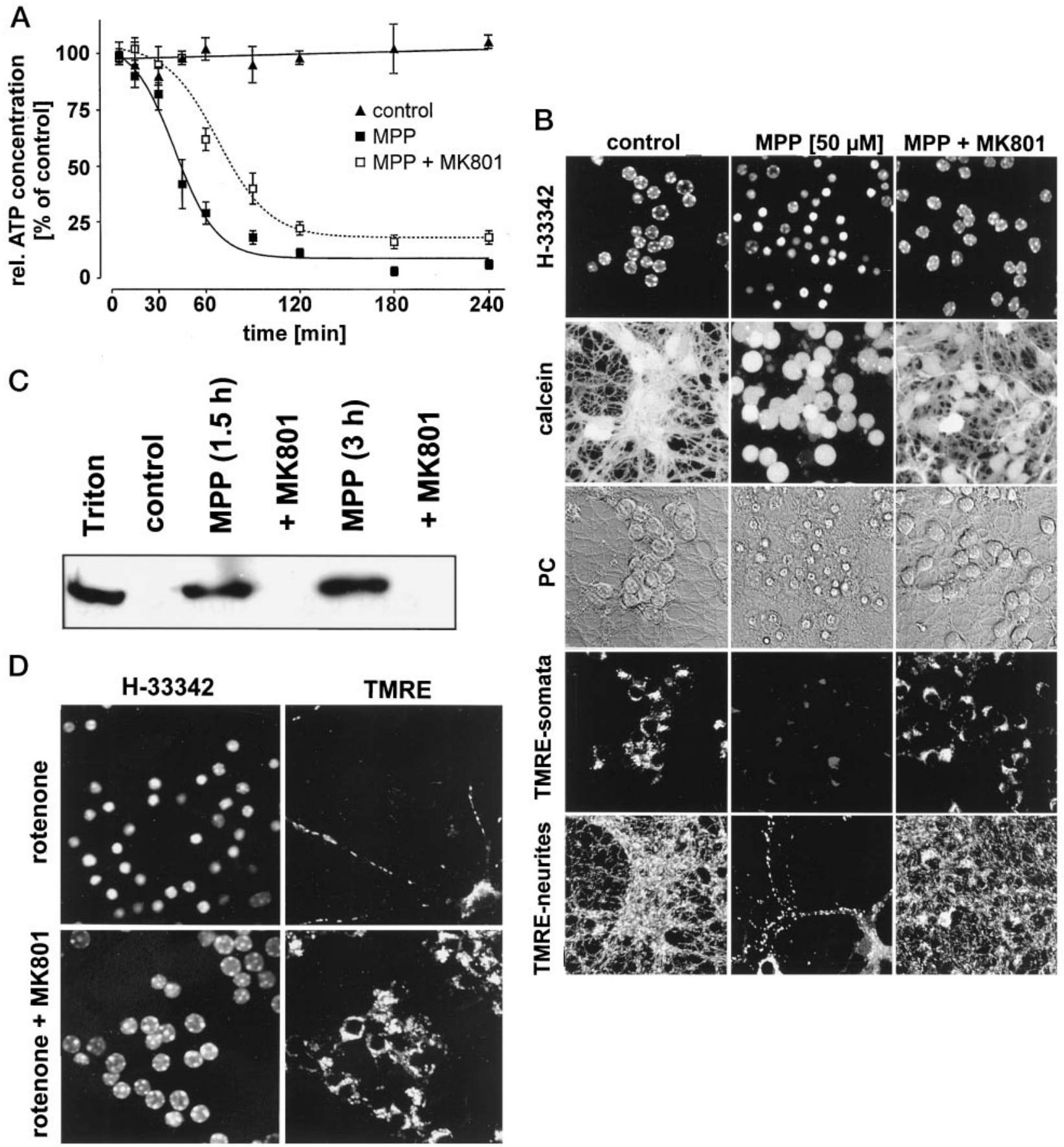

Fig. 3. NMDA-R and prevention of mitochondrial damage caused by $\mathrm{MPP}^{+}$. A, CGC were preincubated for 30 min with solvent $(0.4 \%$ dimethylsulfoxide) or $2 \mu \mathrm{M}$ MK801 and then challenged with $50 \mu \mathrm{M} \mathrm{MPP}{ }^{+}$. At the times indicated, the medium was removed, cells were lysed, and ATP was determined luminometrically. Intracellular ATP content is expressed as percentage of that measured in untreated cells $($ control) at $\mathrm{t}=0(2.8 \mathrm{nmol}$ of ATP/mg of protein). Viability and $\Delta \Psi$ were determined in parallel cultures from the same preparation. TMRE fluorescence did not significantly drop in CGC treated with MK801 + $\mathrm{MPP}^{+}$, whereas it was fully lost after 60-90 min in cells treated with $\mathrm{MPP}^{+}$only. Viability of MPP $+\mathrm{MK}^{+} 01$-treated cells was maintained for $\geq 16 \mathrm{hr}$, whereas nuclear condensation in $\mathrm{MPP}^{+}$-treated neurons started after 45 min. Data represent mean \pm standard deviation of triplicate determinations. B, CGC incubated in control medium, with $50 \mu \mathrm{M} \mathrm{MPP}+$, or with $\mathrm{MPP}^{+}$plus $2 \mu \mathrm{M}$ MK801 were stained after $4 \mathrm{hr}$ with H-33342 (chromatin), calcein (cell membrane integrity), and TMRE (mitochondrial $\Delta \Psi$ ). Samples were imaged by confocal microscopy using fluorescence and polarization contrast $(P C)$. Mitochondria from the axodendritic network (TMRE neurites) and those within the cell body (TMRE somata) were imaged at different focal planes. $\mathrm{MPP}^{+}$-treated neurons had condensed nuclei, whereas the plasma membrane (calcein staining) was still intact. TMRE staining in both neurites and somata disappeared. Only astrocytes (fifth row, middle: one astrocyte is shown with the cell body in the lower right corner and processes extending to the left) retained $\Delta \Psi$ (TMRE staining). MK801 prevented both nuclear condensation and loss of mitochondrial function. All experiments were repeated in at least six cell preparations with similar results. Scale, width of each micrograph corresponds to $108 \mu \mathrm{m}$ in CGC cultures. C, CGC were preincubated with or without $2 \mu \mathrm{M}$ MK801 and challenged with $50 \mu \mathrm{M}$ MPP ${ }^{+}$. Cytochrome $c$ release into the cytosol was determined by Western blot. Cells treated with $0.5 \%$ Triton X-100 (Triton) were analyzed to indicate the maximal cytochrome $c$ release. D, CGC were incubated with $25 \mathrm{~nm}$ rotenone or with rotenone plus $2 \mu \mathrm{M}$ MK801. They were stained after $4 \mathrm{hr}$ with $\mathrm{H}-33342$ (chromatin). In rotenone-treated cells, all TMRE staining (mitochondrial $\Delta \Psi$ ) was lost, and nuclei appeared condensed. Astrocyte nuclei and their mitochondria were unaffected (astrocyte in lower right corner with processes extending up and to the left). MK801 prevented nuclear condensation and loss of TMRE. 
ertheless, also when both $\Delta \Psi$ loss and ATP depletion occurred, CGC were protected by MK801. Loss of $\Delta \Psi$ triggered by the complex I inhibitor $\mathrm{MPP}^{+}$could be partially prevented by energizing mitochondria with the complex II substrate methylsuccinate (Table 1).

The role of NO generation and exocytosis in MPP $^{+}$ toxicity. Endogenous NO production contributes to MPTPinduced pathology in vivo (Hantraye et al., 1996). Thus, we tested whether endogenously formed NO was involved in our system. Inhibitors of the neuronal NO synthase did not reduce $\mathrm{MPP}^{+}$-induced apoptosis, nor did they modify other cytotoxicity parameters (Fig. 2A). One mechanism potentially involved in neuronal excitotoxic death is the activation of the enzyme PARP downstream to NO-mediated DNA damage (Zhang et al., 1994). The mechanism of $\mathrm{MPP}^{+}$-induced excitotoxicity in CGC was, however, unrelated to PARP activation because neurons prepared from $\mathrm{PARP}^{-/-}$mice were equally sensitive as those from wild-type mice (Fig. 1). Together, these findings suggested that $\mathrm{MPP}^{+}$has the potential to activate excitotoxic mechanisms independent of NO generation.

A proapoptotic mechanism requiring NMDA-Rs involves the release of NMDA-R agonists from presynaptic terminals. This mechanism has been described in neurons treated with NO donors or with $\mathrm{ONOO}^{-}$(Leist et al., 1997a, 1997d). Prevention of $\mathrm{MPP}^{+}$-induced apoptosis by the competitive glutamate antagonist AP5 suggested that the release of NMDA-R agonists is a possible upstream mechanism, which also triggered excitotoxicity in this system. To test this assumption, we used the clostridial toxins BoNT/C and tetanus toxin, which are known to block exocytosis. Pretreatment of CGC with the toxins prevented apoptosis completely when cells were exposed to low $\mathrm{MPP}^{+}$concentrations for a limited time (Fig. 4A). When the intensity of insult was increased (e.g., $100 \mu \mathrm{M} \mathrm{MPP}{ }^{+}$), the clostridial toxins became less effective, although cultures were still completely protected by MK801 or AP5. These data suggest that with high levels of $\mathrm{MPP}^{+}$, apoptosis was not mediated by vesicular exocytotic glutamate release. The reversal of the glutamate transporter (Szatkowski and Attwell, 1994) may play a role under these circumstances. A role for increased extracellular glutamate concentrations is further suggested by experiments performed with inhibitors of the glutamate uptake system. $\alpha$-Aminoadipic acid (250 $\mu \mathrm{M})$ significantly accelerated or enhanced $\mathrm{MPP}^{+}$-induced CGC apoptosis (not shown).

Further support for an excitotoxic mechanism at the base of $\mathrm{MPP}^{+}$-mediated neuronal apoptosis came from the findings that $\mathrm{MPP}^{+}$triggered a sustained increase of $\left[\mathrm{Ca}^{2+}\right]_{\mathrm{i}}$ that was prevented by MK801 (Fig. 4, B and C). Similar data were obtained with rotenone (Fig. 5A). Despite the strong rise in $\left[\mathrm{Ca}^{2+}\right]_{\mathrm{i}}, \mathrm{MPP}^{+}$challenged neurons retained the $\mathrm{Ca}^{2+}$ fluorescent indicators for up to $4 \mathrm{hr}$ (i.e., they retained plasma membrane impermeability to the $\mathrm{Ca}^{2+}$ dyes when nuclei had already undergone condensation).

The role of proteases in $\mathrm{MPP}^{+}$- or rotenone-induced autocrine excitotoxicity. To further characterize the steps between NMDA-R-mediated $\left[\mathrm{Ca}^{2+}\right]_{\mathrm{i}}$ increase and cell death, we examined the role of cellular thiol proteases. Inhibition of either caspases or calpains was sufficient to block apoptosis elicited by $\mathrm{MPP}^{+}$concentrations up to $50 \mu \mathrm{M}$ (Fig. 6, A and B). The same set of inhibitors also protected CGC from the apoptosis induced by $50 \mathrm{~nm}$ rotenone ( $\geq 80 \%$ cells remained viable in the presence of each of five different protease inhibitors) (Fig. 6E). Because all available inhibitors lack an absolute specificity for a single type of proteases (Villa et al., 1997), we used three or five structurally different agents for each class of proteases with similar results. Inactive control peptides $(\leq 100 \mu \mathrm{M})$ with similar end groups as the inhibitors were not effective. We also established sensitive in vitro assays with purified calpain or recombinant caspase-3 to test cross-reactivity of the inhibitors between the two classes of thiol proteases: for instance, z-D-cbk was found to be a highly potent inhibitor of caspase-3 $\left(\mathrm{IC}_{50}<200 \mathrm{nM}\right)$ without any inhibitory effect on calpains $\left(\mathrm{IC}_{50}>200 \mu \mathrm{M}\right)$. Calp II showed exactly opposite characteristics. Thus, both caspases and calpains seemed to be required to mediate apoptosis of CGC challenged with $50 \mu \mathrm{M} \mathrm{MPP}^{+}$. Cells protected by protease inhibitors remained viable for $\geq 24 \mathrm{hr}$, when they received new medium or CSS. At very high intensities of insult (e.g., $100 \mu \mathrm{M} \mathrm{MPP}{ }^{+} ;>4$-hr toxin exposure), the protective effect of protease inhibitors was bypassed.

To gather direct evidence for intracellular proteolysis, we measured cleavage of fodrin (nonerythroid spectrin), a cytoskeletal protein, that is cleaved in neurons and various apoptotic cells by different isoenzymes of the caspase family, as well as by calpains (Nath et al., 1996; Leist et al., 1997d). $\mathrm{MPP}^{+}$-triggered fodrin proteolysis was prevented/reduced by different caspase and calpain inhibitors in a concentrationdependent fashion. The extent of inhibition of proteolysis at different protease inhibitor concentrations correlated with the extent of protection from apoptosis (Fig. 6C). Fodrin proteolysis also was blocked by MK801, but not by z-F-cmk, an inactive analogue of caspase inhibitors (Fig. 6D).

Protease inhibitors act downstream to the $\mathrm{Ca}^{2+}$ influx via the NMDA-R. Two sets of experiments were performed to test whether protease inhibitors indeed acted downstream of NMDA-R-mediated $\left[\mathrm{Ca}^{2+}\right]_{\mathrm{i}}$ increase. First, we measured NMDA-R-mediated $\left[\mathrm{Ca}^{2+}\right]_{\mathrm{i}}$ increases in CGC in the presence of protease inhibitors. None of the peptide inhibitors had a significant inhibitory effect (Fig. 7). Similar experiments were performed using as agonists glutamate, kainate, or high $\left[\mathrm{K}^{+}\right]$. None of the protease inhibitors blocked $\left[\mathrm{Ca}^{2+}\right]_{\mathrm{i}}$ increase due to these stimuli (not shown).

In addition, we examined the protective effect of $\mathrm{z}-\mathrm{D}$-cbk and Ac-YVAD-cmk against glutamate and kainate-induced toxicity. Similar to the results published recently by Du et al. (1997a), we found small but significant protection (Fig. 6E). Notably, these protective effects were observed only at low concentrations of glutamate receptor agonists $(12-50 \mu \mathrm{M})$, and in our experiments, only $20 \%$ of the neurons were rescued with any concentration of agonist and inhibitor. It seems that the degree of neuronal damage was more easily controlled, and more susceptible to pharmacological intervention, in the indirect excitotoxic model than after direct treatment of neurons with glutamate receptor agonists. This suggests that the role of caspases in excitotoxic neuronal apoptosis is more relevant at very low intensities of challenge or under conditions of indirect excitotoxicity.

The role of proteases and the NMDA-R in MPP $^{+}$. induced chromatin breakdown. Caspase-3 activation has recently been shown to be a direct upstream mechanism leading to oligonucleosomal DNA-fragmentation. In CGC, oligonucleosomal DNA fragmentation was not significantly activated within the first $4 \mathrm{hr}$ after challenge, when most 
other processes relevant to cell death had already occurred. In glutamate-challenged CGC oligonucleosomal DNA fragmentation is a late event and may not be evident at all (Ankarcrona et al., 1995). In analogy with the glutamate model, we observed here high molecular weight DNA fragmentation into 600-, 300-, and 50-kbp fragments in CGC treated with $\mathrm{MPP}^{+}$. This characteristic feature of apoptotic chromatin degradation was prevented by MK801 or by inhibitors of either calpains or caspases (Fig. 8A). This suggests the involvement of a proteolytic step, downstream to the initial $\left[\mathrm{Ca}^{2+}\right]_{\mathrm{i}}$ increase, which results in chromatin breakdown. This proteolytic step does not seem to be linked to caspase-3 activation. Consistent with the lack of oligonucleosomal DNA fragmentation and with the proteolysis pattern of fodrin [caspase-3 forms a $120-\mathrm{kDa}$ fragment, whereas caspase-4, caspase-2, or calpain forms mainly a $150-\mathrm{kDa}$ fragment (Nath et al., 1996)], we did not detect caspase-3-like (DEVD-afc cleavage) activity in CGC challenged with $\mathrm{MPP}^{+}$. Notably, DEVD-afc cleavage activity instead was easily detected in the same cell preparation challenged with colchicine or low $\left[\mathrm{K}^{+}\right]$(Leist et al., 1997d). Further evidence for the absence of caspase- 3 activation in the $\mathrm{MPP}^{+}$model is the lack of processing of procaspase-3 to the active caspase. Procaspase-3 was not cleaved even at a time point where fodrin was already $\geq 90 \%$ cleaved and nuclei were condensed (Fig. 8B).

Prevention of $\mathrm{MPP}^{+}$-induced PS translocation by NMDA-R blockade and caspase inhibition. Transloca-
A

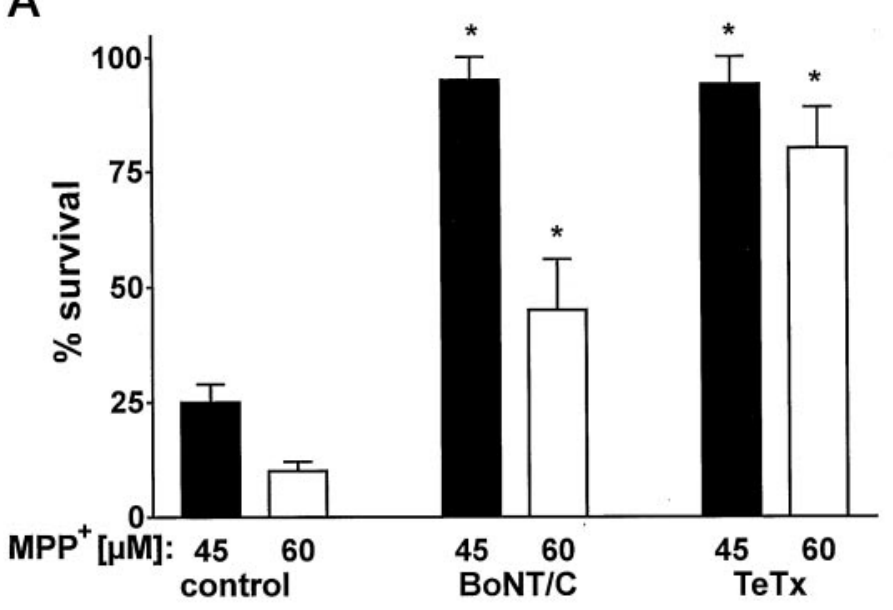

B

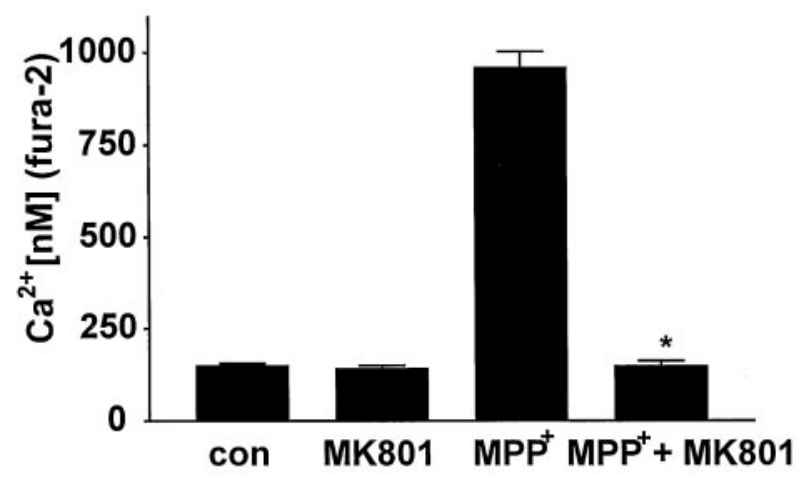

D

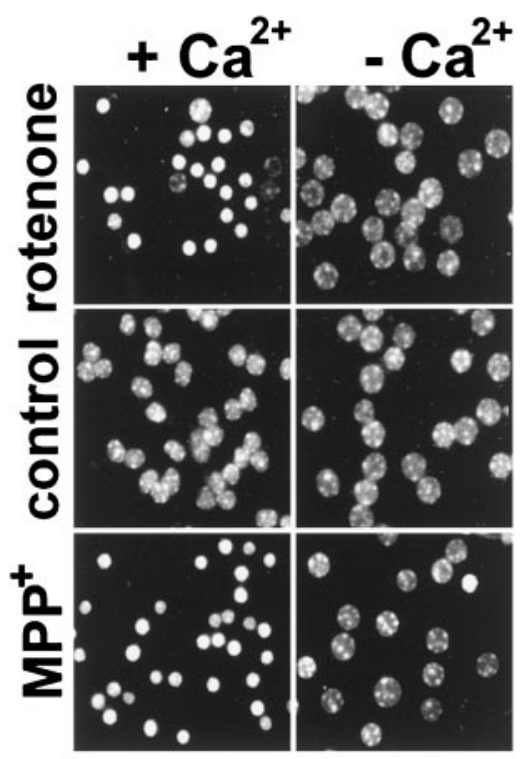

Fig. 4. $\mathrm{MPP}^{+}$-triggered exocytosis and autocrine excitotoxicity in CGC. A, CGC were preincubated for $10 \mathrm{hr}$ with $20 \mathrm{ng} / \mathrm{ml} \mathrm{BoNT} / \mathrm{C}(130 \mathrm{pM})$ or 500 $\mathrm{ng} / \mathrm{ml}$ tetanus toxin $\left(3 \mathrm{nM}\right.$ ) before they were challenged with $\mathrm{MPP}^{+}$. The medium was exchanged $4 \mathrm{hr}$ after challenge for CSS, and survival was determined after $18 \mathrm{hr}$ by MTT assay. Data are mean \pm standard deviation from triplicate determinations. $*, p \leq 0.05$. B, CGC were challenged with $50 \mu \mathrm{M} \mathrm{MPP}{ }^{+} \pm \mathrm{MK} 801$. After $2 \mathrm{hr}, \mathrm{CGC}$ were loaded with Fura-2, and $\left[\mathrm{Ca}^{2+}\right]_{\mathrm{i}}$ was determined by ratiometric video imaging and in situ calibration. Data are mean \pm standard deviation from 16-20 neurons. Similar results were obtained in three different cell preparations. The $\left[\mathrm{Ca}^{2+}\right]_{\mathrm{i}}$ measured in $\mathrm{MPP}^{+}$-treated CGC is close to the saturation range of the indicator and therefore may be $\geq 1 \mu \mathrm{M} . *, p \leq 0.05$. C, CGC were pretreated with DMSO alone (solvent) or $2 \mu \mathrm{M} \mathrm{MK801} \mathrm{(MK801)} \mathrm{and} \mathrm{loaded} \mathrm{with} \mathrm{fluo-3} \mathrm{acetoxymethyl} \mathrm{ester} \mathrm{before} \mathrm{they} \mathrm{were} \mathrm{challenged} \mathrm{with} 120 \mu \mathrm{M}$ MPP ${ }^{+}$. The increase of $\left[\mathrm{Ca}^{2+}\right]_{\mathrm{i}}$ in time (relative fluo-3 fluorescence) was measured by confocal microscopy. Data are mean \pm standard error from $10-15$ neurons. D, CGC were challenged in CSS containing $1.8 \mathrm{~mm} \mathrm{Ca}{ }^{2+}\left(+\mathrm{Ca}^{2+}\right)$ or no nominal $\mathrm{Ca}^{2+}\left(-\mathrm{Ca}^{2+}\right)$ with $100 \mu \mathrm{M} \mathrm{MPP}^{+}$or $100 \mathrm{~nm}$ rotenone. After $3 \mathrm{hr}$, apoptosis was determined by staining of cells with H-33342 and counting of the percentage of condensed nuclei. In three independent experiments, the average apoptosis was $84 \pm 7 \%\left(\mathrm{MPP}^{+}+\mathrm{Ca}^{2+}\right), 88 \pm 8 \%\left(\right.$ rotenone $\left.+\mathrm{Ca}^{2+}\right)$, and $\leq 10 \%$ under all other conditions. 
tion of PS from the inner to the outer surface of the plasma membrane is an early and specific event in apoptosis (Leist et $a l ., 1997 b, 1997 \mathrm{~d}$ ), which seems to be dependent on caspase activation, at least in tumor cells. In CGC, $\mathrm{MPP}^{+}$caused PS translocation, as detected by annexin $\mathrm{V}$ staining, within 1-2 $\mathrm{hr} . \mathrm{MPP}^{+}$-treated neurons stained intensively when the first signs of chromatin condensation were visible and well before the nucleus became fully pyknotic. CGC remained stainable for several hours until membrane permeability was lost and membranes were degraded. Virtually all neurons with condensed chromatin had lost plasma membrane lipid asymmetry $\left(\geq 90 \%\right.$ annexin V-positive neurons at $\mathrm{MPP}^{+}$concentrations of $\geq 50 \mu \mathrm{M}$ in four independent experiments). Often, large spherical membrane blebs were formed from the axons, which also stained positively with annexin $\mathrm{V}$ and had an intact membrane. Notably, annexin $\mathrm{V}$ binding to neuronal
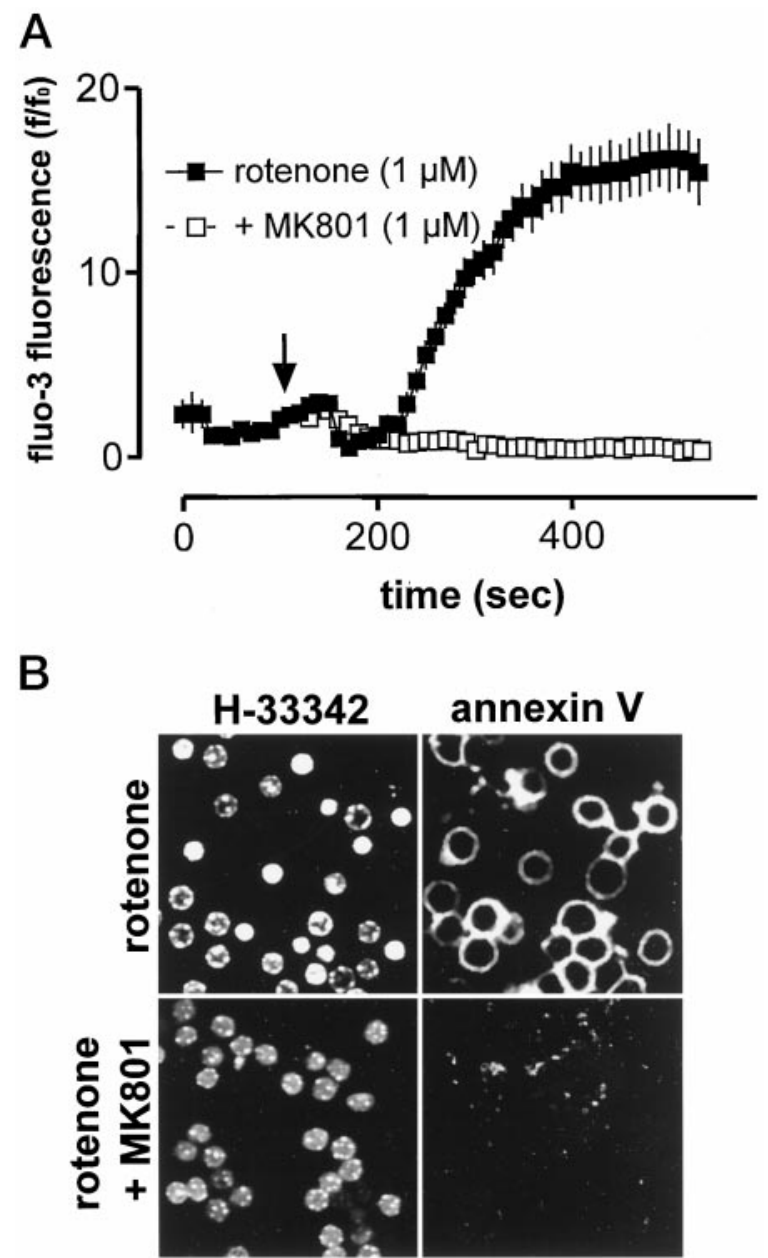

Fig. 5. MK801 prevents rotenone-induced $\mathrm{Ca}^{2+}$ increase and PS translocation. A, CGC were incubated with (open symbols) or without (filled symbols) $1 \mu \mathrm{M}$ MK801. Rotenone $(1 \mu \mathrm{M})$ was added as indicated (arrow), and the change of $\left[\mathrm{Ca}^{2+}\right]_{i}$ was followed by confocal imaging of fluo-3 fluorescence. Data represent the mean \pm standard deviation from 15-25 cells in three independent experiments. B, CGC were pretreated with 1 $\mu \mathrm{M}$ MK801 or not treated. At $2 \mathrm{hr}$ after the addition of rotenone (25 nM), cells were stained with fluorescent annexin V (PS translocation) and H-33342 (chromatin structure). Fluorescence images were collected by confocal microscopy. Note that cells with only marginally condensed nuclei are already annexin $\mathrm{V}$ positive. Phosphatidylserine translocation (annexin V stainability) was completely prevented by MK801. Data are representative for four experiments in three independent cell preparations. bodies was completely prevented by MK801 (Fig. 9) and was triggered by direct exposure to glutamate (not shown), which suggests that PS translocation is linked to NMDA-R-mediated $\mathrm{Ca}^{2+}$ influx and not to direct $\mathrm{MPP}^{+}$actions. In addition, exposure to rotenone induced PS translocation, which was inhibited by MK801 (Fig. 5B). Annexin V labeling also was inhibited by the caspase inhibitor $\mathrm{z}-\mathrm{D}$-cbk, in agreement with the view that caspases also are pivotal for this feature of neuronal apoptosis (Fig. 9).

\section{Discussion}

MPP $^{+}$elicits autocrine excitotoxicity in CGC. Our results show that $\mathrm{MPP}^{+}$induces apoptosis of cultured CGC by eliciting autocrine excitotoxicity. $\mathrm{MPP}^{+}$can induce either apoptosis or necrosis in vivo (Tatton and Kish, 1997), and previous studies have shown that either form of cell death can be induced in vitro, by mechanisms unrelated to excitotoxicity (Marini et al., 1989; Du et al., 1997b). Low MPP ${ }^{+}$ concentrations predominantly elicit apoptosis, whereas high concentrations trigger necrosis (Hartley et al., 1994; Du et al., 1997b). In animals, removal of glutamatergic inputs (decortication), blockers of glutamate release, or NMDA-R antagonists reduce MPTP- and $\mathrm{MPP}^{+}$-induced striatal damage and dopamine depletion (Srivastava et al., 1993) or loss of dopaminergic neurons in the substantia nigra (Turski et al., 1991).

Because binding to complex I (Kilbourn et al., 1997) is the primary known biochemical effect of $\mathrm{MPP}^{+}$, putative excitotoxic mechanisms should be secondary to the initial mitochondrial dysfunction. Energy failure sensitizes neurons to excitotoxicity (Henneberry et al., 1989) and fosters the release of excitotoxic mediators (Szatkowski and Attwell, 1994). In addition, mitochondria represent a target of excitotoxic mechanisms (Leist and Nicotera, 1998), and mitochondrial damage can aggravate the initial damage by releasing $\mathrm{Ca}^{2+}$, reactive oxygen species, and factors essential for apoptotic protease activation (Leist and Nicotera, 1997). Therefore, the exact contribution of mitochondria to $\mathrm{MPP}^{+}$-stimulated excitotoxicity is complicated by the cyclic nature of the events (initial direct inhibition and further mitochondrial damage and ATP depletion caused by excitotoxicity).

Of all the cytotoxic events elicited by $\mathrm{MPP}^{+}$and examined in this study, enhanced glucose consumption and ATP depletion were the only ones that were not ameliorated by NMDA-R blockade and thus seemed to be primary effects of $\mathrm{MPP}^{+}$. It has been suggested earlier that mitochondrial inhibition by NO would result in ATP depletion and disturb $\left[\mathrm{Ca}^{2+}\right]_{\mathrm{i}}$ homeostasis even in the presence of glucose (Brorson et al., 1997). This is confirmed by our findings with both $\mathrm{MPP}^{+}$and 3-NP. Therefore, ATP depletion caused by $\mathrm{MPP}^{+}$ seems to be the most plausible triggering event for excitotoxicity. Notably, both the collapse of $\Delta \Psi$ and the loss of cytochrome $c$ were prevented when CGC were pretreated with the NMDA-R antagonist MK801 (i.e., major components of mitochondrial damage were the result of secondary excitotoxicity and not the direct effects of $\mathrm{MPP}^{+}$on the respiratory chain). In agreement with this view, low concentrations of four other mitochondrial inhibitors did not cause massive mitochondrial failure per se (i.e., under conditions when the NMDA-R was blocked) but triggered rapid cell death when the NMDA-R was functional. 
Release of NMDA-R agonists in CGC treated with $\mathrm{MPP}^{+}$ may occur by two different mechanisms (Szatkowski and Attwell, 1994). First, release may occur by exocytosis. This process may be relevant with lower $\mathrm{MPP}^{+}$concentrations and shorter exposure times, when ATP levels are still high enough to promote the fusion of neurotransmitter vesicles with the presynaptic membrane or when the pool of vesicles that has already been primed for exocytosis is released. The reduction in $\mathrm{MPP}^{+}$toxicity by tetanus toxin or botulinum toxin suggests that this mechanism is operative in our system, at least with lower $\mathrm{MPP}^{+}$concentrations. The relevance of this release mechanism for secondary excitotoxicity has also been demonstrated in models of oxygen-glucose depriva-

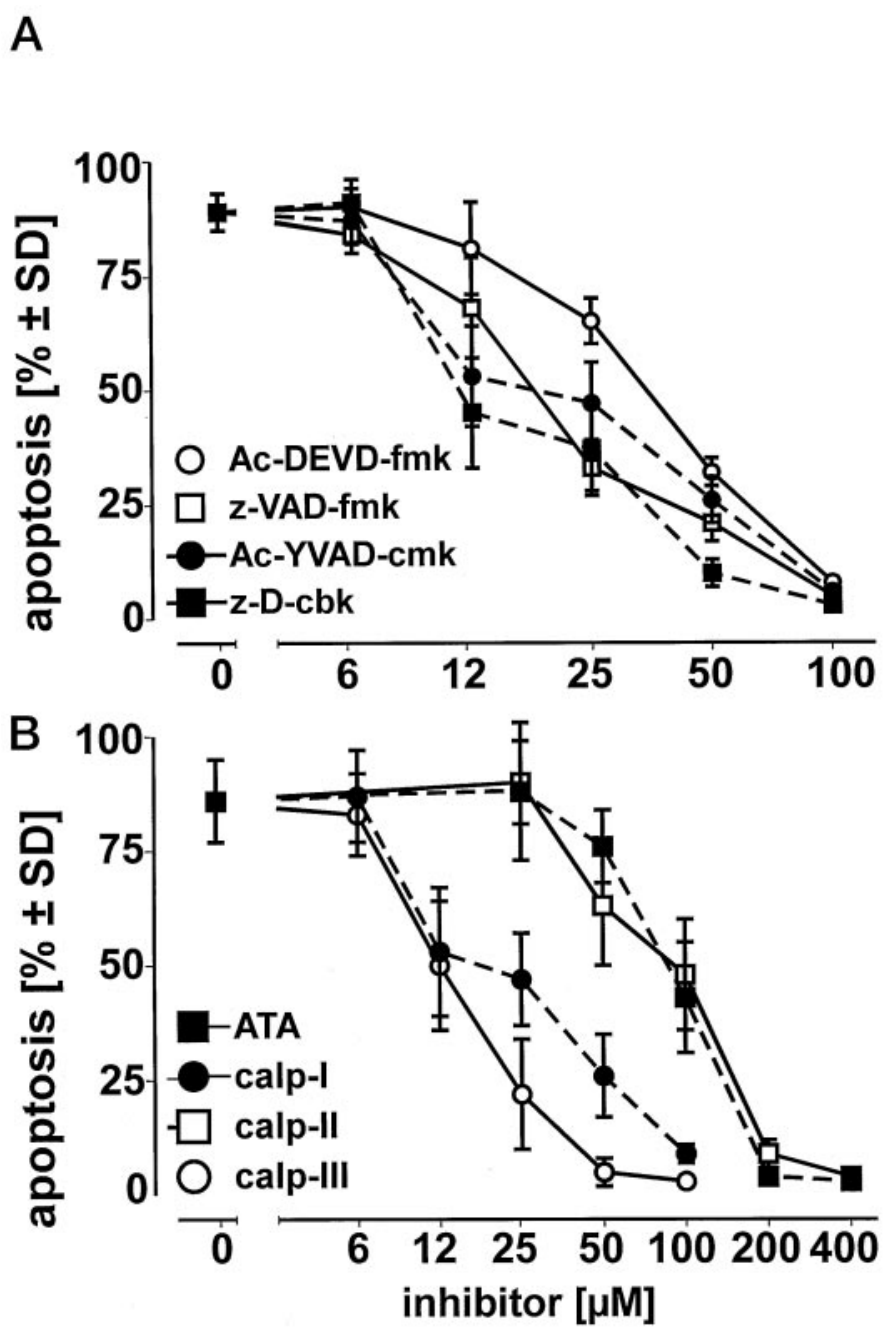

tion (Monyer et al., 1992) or NO-triggered excitotoxicity (Leist et al., 1997a). Second, glutamate may be released by the reversal of the glutamate transporter. This mechanism is likely to operate in CGC exposed to high $\mathrm{MPP}^{+}$concentrations for longer times. It does not require ATP but rather is triggered by intracellular and extracellular ionic changes, which occur under conditions of ATP loss. Support for this hypothesis comes from the finding that intracellular ATP levels declined slowly immediately after exposure to $\mathrm{MPP}^{+}$ but then reached very low levels. At early stages, ATP production may have been maintained by residual mitochondrial production or glycolysis (Budd and Nicholls, 1996). Accordingly, the addition of $10 \mathrm{~mm}$ glucose or methylsuccinate to the
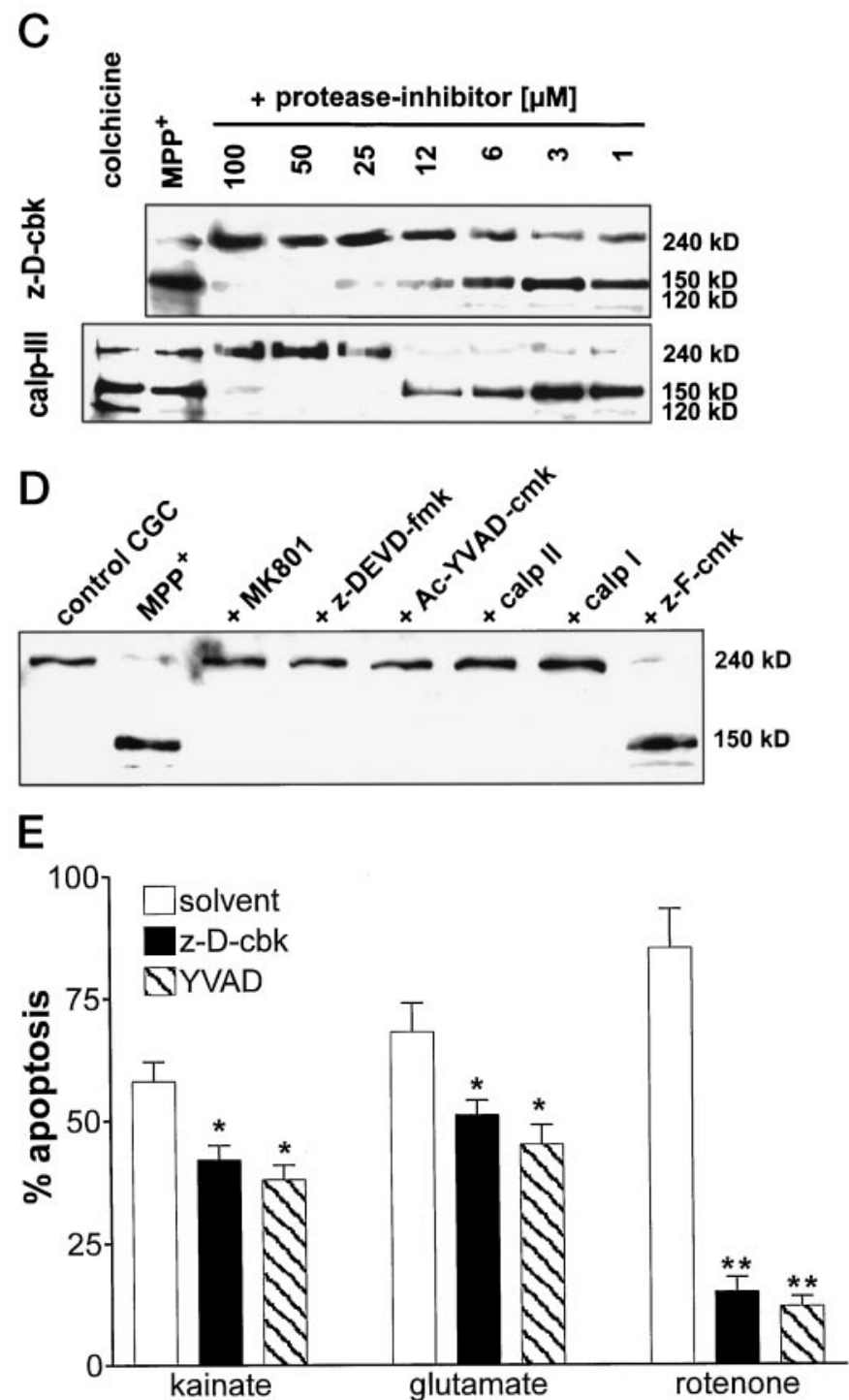

Fig. 6. Caspase or calpain inhibitors prevent $\mathrm{MPP}^{+}$triggered intracellular proteolysis and apoptosis. CGC were incubated with (A) various caspase inhibitors or (B) calpain inhibitors at the concentrations indicated (logarithmic scale). At 30 min later, they were challenged with $50 \mu \mathrm{M}$ MPP ${ }^{+}$. The percentage of apoptotic neurons was determined by counting the number of cell bodies. Data are mean \pm standard deviation of triplicate determinations. C, Inhibition of fodrin proteolysis was studied by Western blotting of extracts from CGC pretreated with seven different concentrations of the caspase inhibitor z-D-cbk (top) or the calpain inhibitor calp III (bottom) and challenged with $50 \mu \mathrm{M} \mathrm{MPP}^{+}$. As positive control for fodrin proteolysis, we used the proapoptotic toxin colchicine $(1 \mu \mathrm{M})$. Colchicine treatment (12 hr) produced proteolytic fragments of $150 \mathrm{and} 120 \mathrm{kDa}$ (bottom, first lane), whereas $\mathrm{MPP}^{+}$(4-hr treatment) mainly produced the $150-\mathrm{kDa}$ fragment. D, CGC were pretreated with various caspase or calpain inhibitors (100 $\left.\mu \mathrm{M}\right)$ or MK801 $(2 \mu \mathrm{M})$, or the inactive caspase inhibitor analogue z-F-cmk, before they were challenged with $\mathrm{MPP}^{+}(50 \mu \mathrm{M})$ for $4 \mathrm{hr}$. Fodrin proteolysis was analyzed by Western blot. E, CGC were pretreated with z-D-cbk $(100 \mu \mathrm{M})$ or Ac-YVAD-cmk (YVAD; $100 \mu \mathrm{M})$ before they were exposed to $50 \mu \mathrm{M}$ kainate, $25 \mu \mathrm{M}$ glutamate, or $50 \mathrm{~nm}$ rotenone for $90 \mathrm{~min}$. Then, medium was exchanged for CSS plus glucose. Apoptosis was quantified by staining neurons with $\mathrm{H}-33342$ and determining the percentage of condensed nuclei. Data are mean values from triplicate determinations. $*, p<0.05 ; * *, p<0.01$ solvent versus inhibitor. 
culture medium significantly delayed $\mathrm{MPP}^{+}$-induced apoptosis and ATP depletion.

Mechanisms of indirect excitotoxicity. Several mechanisms have been implicated in direct excitotoxic neuronal death, including excessive NO production and subsequent activation of PARP (Zhang et al., 1994), mitochondrial alterations (Ankarcrona et al., 1995), and protease activation (Siman and Noszek, 1988; Du et al., 1997a). Although brain NO synthase has an aggravating role in some models of excitotoxicity, NO plays a minor role as a direct mediator of toxicity in CGC (reviewed in Leist et al., 1997a). CGC strongly express nitric oxide synthase and therefore may have developed mechanisms to prevent direct NO toxicity. Consistent with this assumption, $\mathrm{MPP}^{+}$toxicity was not altered by nitric oxide synthase inhibitors. PARP activation is triggered by DNA damage, which may be caused by NO (Zhang et al., 1994). We found no alteration in the cell death rate or mode of cell death in cells prepared from $\mathrm{PARP}^{-1-}$ mice, which further supports the lack of involvement of $\mathrm{NO}$ in $\mathrm{MPP}^{+}$ toxicity. In contrast, in CGC stimulated with $\mathrm{MPP}^{+}$, mitochondrial dysfunction and protease activation seem to be key events, which mediate excitotoxic cell death.

Proteases in excitotoxic death. Apoptosis is associated with the activation of a proteolytic cascade, probably involving different sets of proteases, which operate virtually at all stages of the cell death program (i.e., signaling, control, and execution) (Villa et al., 1997). Here, we found that both caspases and calpains were activated downstream to the NMDA-R-mediated $\left[\mathrm{Ca}^{2+}\right]_{\mathrm{i}}$ increase and upstream of PS translocation, nuclear condensation, and DNA fragmentation. Under appropriate conditions, cells pretreated with protease inhibitors survived $\mathrm{MPP}^{+}$challenge for several days. Obviously, different sets of proteases can interact to cause neuronal death; examples include caspases and calpains (Nath et al., 1996; Jordán et al., 1997; current study), different caspases and serine proteases (Stefanis et al., 1997), and caspases plus the proteasome.

Very recent findings describe caspase-3 activation in neurons exposed to $\mathrm{MPP}^{+}$(Du et al., 1997d). In this model, cell

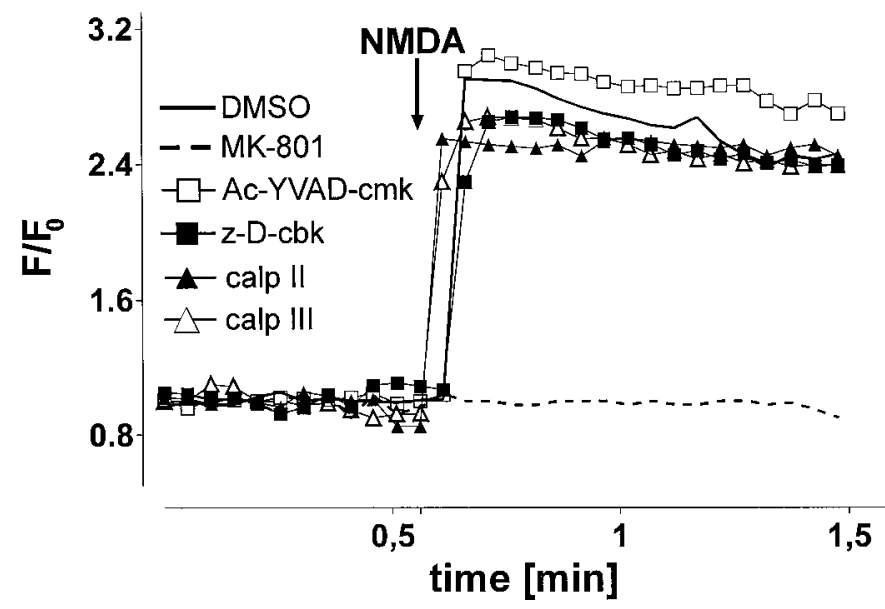

Fig. 7. Protease inhibitors do not inhibit NMDA-R-mediated neuronal $\mathrm{Ca}^{2+}$ increase. CGC were pretreated with various protease inhibitors $(100 \mu \mathrm{M})$ or MK801 and loaded with fluo-3. They were challenged with $200 \mu \mathrm{M}$ NMDA as indicated, and the fluorescence increase $\left(\mathrm{F} / \mathrm{F}_{0}\right)$ was recorded by confocal microscopy. Data were obtained from 10-15 neurons, and experiments were repeated in three different CGC preparations. death was slow (72 hr) and did not involve excitotoxic mechanisms. In contrast, caspase- 3 activity did not seem to be involved in our experimental paradigm: (i) procaspase-3 was not proteolytically activated; (ii) $\mathrm{MPP}^{+}$did not elicit DEVDafc cleavage activity (specific for caspases-3/7), which is instead stimulated by several other proapoptotic agents under similar conditions (Leist et al., 1997d); and (iii) the cleavage pattern of fodrin was not typical for caspase-3.

Excitotoxic apoptosis. Excitotoxic cell death may occur by either apoptosis or necrosis. Seemingly divergent observations are reconciled by the finding that the intensity of insult may determine the mode of cell death (e.g., Ankarcrona et al., 1995; Du et al., 1997a; Leist and Nicotera, 1998) and that excessive $\mathrm{Ca}^{2+}$ entry may convert the mode of cell death in some cases from apoptosis to necrosis (reviewed in Leist et al., 1997d). Intracellular ATP levels seem to be critical in determining the shape of cell death (Ankarcrona et al., 1995; Leist et al., 1997c), and ATP may be required at multiple sites. For instance, ATP/dATP is required for the acti-

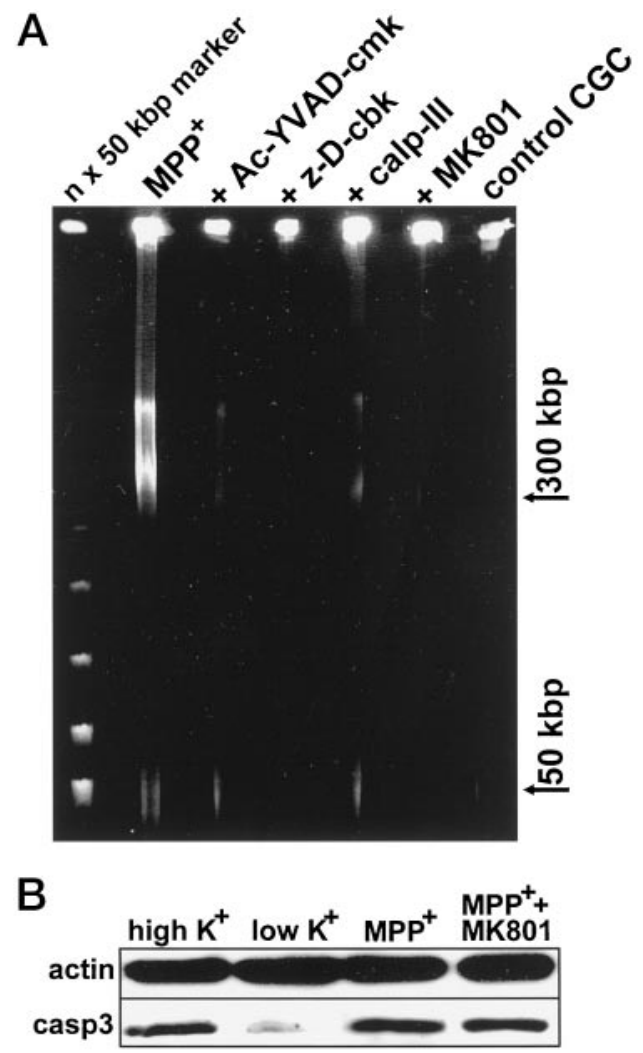

Fig. 8. $\mathrm{MPP}^{+}$-triggers NMDA-R- and caspase-dependent apoptotic chromatin degradation but not procaspase-3 proteolysis. A, CGC were preincubated for 30 min with $100 \mu \mathrm{M}$ Ac-YVAD-cmk, z-D-cbk, calp III, or $2 \mu \mathrm{M}$ MK801 or solvent control only. Then, they were challenged with $50 \mu \mathrm{M}$ $\mathrm{MPP}^{+}$or they were left unchallenged (control CGC). After $4 \mathrm{hr}$, incubations were stopped and DNA fragmentation was analyzed by field-inversion gel electrophoresis. Less than 5\% of CGC had lost membrane permeability at that time point. B, CGC were challenged with $\mathrm{MPP}^{+}$in the presence and absence of MK801. Cells were harvested after $3 \mathrm{hr}$, when fodrin was already nearly maximally cleaved (see Fig. 6) and $>80 \%$ of apoptotic nuclei were scored. Alternatively, apoptosis was induced by switching cells to low $\mathrm{K}^{+}$medium for $24 \mathrm{hr}$ (low $\mathrm{K}^{+}$; $\sim 75 \%$ apoptotic neurons). Control cells were incubated for $24 \mathrm{hr}$ in high $\mathrm{K}^{+}(<10 \%$ apoptotic neurons). A decrease of procaspase-3 (casp3) due to activation of the protease is seen in the low $\mathrm{K}^{+}$model but not in the $\mathrm{MPP}^{+}$model. Activated murine caspase-3 was not detected by the antibody used. Therefore, the blot membrane was redeveloped after stripping with an anti-actin antibody to confirm equal protein loading. 
vation of caspase-3, which is a central protease in many apoptosis models. Here, we show that apoptosis proceeds in the absence of procaspase- 3 processing. This also may explain the lack of oligonucleosomal DNA fragmentation, which is a direct consequence of caspase-3 activation. In $\mathrm{MPP}^{+}$treated neurons, other cell death proteases may be activated by mechanisms not directly requiring ATP.

This work and previous evidence suggest that in mild excitotoxicity, caspases are among the direct executors of apoptosis. In addition to their degradative role in cell death, caspases may participate in the multiple positive feedback reactions that characterize secondary excitotoxicity; examples may include cleavage of proteins regulating $\left[\mathrm{Ca}^{2+}\right]_{\mathrm{i}}$ homeostasis or energy generation. Multiple further positive feedbacks link reactive oxygen species, glutamate release, disturbed $\left[\mathrm{Ca}^{2+}\right]_{\mathrm{i}}$ homeostasis, mitochondrial defects, energy depletion, and proteolysis. Establishment of such vicious circles may be blocked at an early stage by inhibiting any of the looping processes. Accordingly, we found that blocking the cycle of events at different sites (clostridial toxins, NMDA-R antagonists, antiproteases, glucose) prevented cell death and the associated biochemical features.

In neuropathological situations, these reciprocal interactions would form the basis of intricate vicious loops that are not likely to be interrupted by a single agent once they are fully established. In line with this view, caspase inhibitors

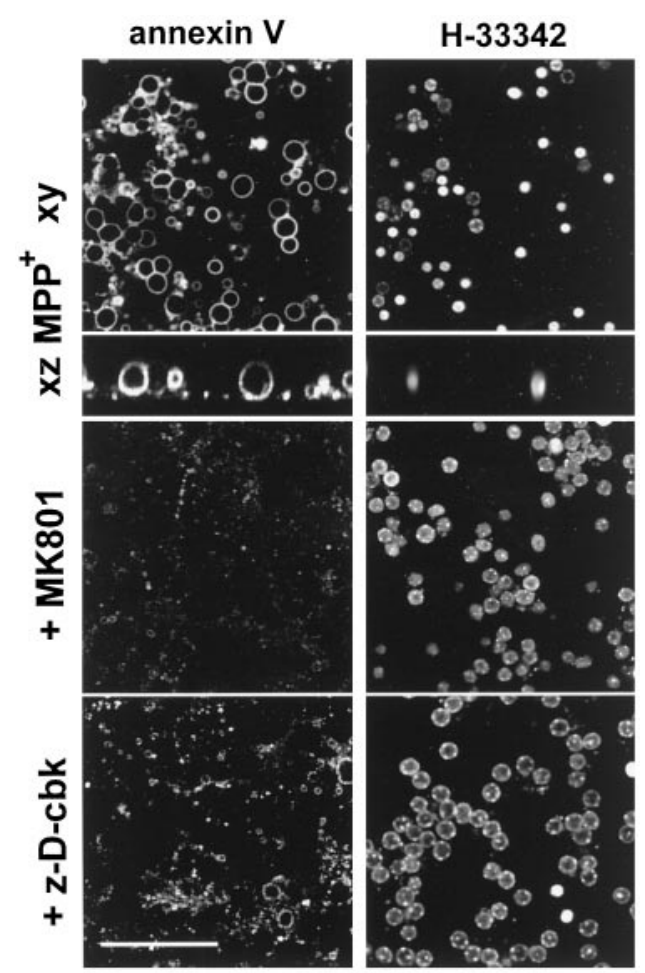

Fig. 9. $\mathrm{MPP}^{+}$triggers NMDA-R- and caspase-dependent apoptotic PS translocation. CGC were incubated with $\mathrm{MPP}^{+}$for $2 \mathrm{hr}$ before they were stained with FITC-annexin V and H-33342 and imaged by confocal microscopy. Top, an $x y$ section through the cell bodies (4 $\mu \mathrm{m}$ from coverslip). Apoptotic nuclei seem to be condensed and hyperfluorescent and are surrounded by annexin V-stained membranes. A transversal section $(x z$ plane) demonstrates that the entire surface of the apoptotic neurons plus some non-chromatin-containing blebs formed from the axonal projections are surface stained with annexin V. Neurons that had been preincubated with z-D-cbk or MK801 did not condense and did not stain with annexin V. only partially protect CGC lethally challenged with glutamate receptor agonists. Also, indirect excitotoxicity due to $\mathrm{NO}$ or $\mathrm{MPP}^{+}$is prevented by protease inhibitors only when the insult is relatively mild (Leist et al., 1997d; current study). This may become important for the design of therapeutic strategies. Protease inhibitors may become maximally effective in preventing neuronal death only when combined with agents reducing the overall intensity of the insult (e.g., glutamate antagonists). The elucidation of key sequences of these vicious circles and a possible hierarchy of events is the subject of ongoing research.

\section{Acknowledgments}

We gratefully acknowledge the excellent technical assistance of $\mathrm{H}$. Naumann and T. Schmitz We are grateful to Dr. Zhao Qi Wang (IARC, Lyon, France) for the gift of the $\mathrm{PARP}^{-1-}$ mice and to Dr. C. Montecucco (University of Padova, Padova, Italy) for the clostridial toxins.

\section{References}

Abele AE, Scholz KP, Scholz WK, and Miller RJ (1990) Excitotoxicity induced by enhanced excitatory neurotransmission in cultured hippocampal pyramidal neurons. Neuron 2:413-419.

Ankarcrona M, Dypbukt JM, Bonfoco E, Zhivotovsky B, Orrenius S, Lipton SA, and Nicotera P (1995) Glutamate-induced neuronal death: a succession of necrosis or apoptosis depending on mitochondrial function. Neuron 15:961-973.

Beal MF (1996) Mitochondria, free radicals, and neurodegeneration. Curr Opin Neurobiol 6:661-666.

Brorson JR, Sulit RA, and Zhang H (1997) Nitric oxide disrupts Ca-2+ homeostasis in hippocampal neurons. J Neurochem 68:95-105.

Budd SL and Nicholls DG (1996) Mitochondria, calcium regulation, and acute glutamate excitotoxicity in cultured cerebellar granule cells. J Neurochem 67:2282 2291

Choi DW and Rothman SM (1990) The role of glutamate neurotoxicity in hypoxicischemic neuronal death. Annu Rev Neurosci 13:171-182.

Du Y, Bales KR, Dodel RC, Hamilton-Byrd E, Horn JW, Czilli DL, Simmons LK, Ni B, and Paul SM (1997a) Activation of a caspase 3-related cysteine protease is required for glutamate-mediated apoptosis of cultured cerebellar granule neurons. Proc Natl Acad Sci USA 94:11657-11662.

Du Y, Dodel RC, Bales KR, Jemmerson R, Hamilton-Byrd E, and Paul SM (1997b) Involvement of a caspase-3-like cysteine protease in 1-methyl-4-phenylpyridinium-mediated apoptosis of cultured cerebellar granule neurons. J Neurochem 69:1382-1388.

Ferrante RJ, Brouillet E, Palfi S, Kowall NW, Hantraye P, and Beal MF (1997) Mitochondrial dysfunction as a model for Huntington's disease using the electron transport chain inhibitor 3-nitropropionic acid, in Mitochondria and Free Radicals in Neurodegenerative Diseases (Beal MF, Howell N, and Bodis-Wollner I, eds) pp 229-244, Wiley-Liss, New York.

Hantraye P, Brouillet E, Ferrante R, Palfi S, Dolan R, Matthews RT, and Beal MF (1996) Inhibition of neuronal nitric oxide synthase prevents MPTP-induced parkinsonism in baboons. Nat Med 2:1017-1021.

Hartley A, Stone JM, Heron C, Cooper JM, and Schapira AHV (1994) Complex I Inhibitors induce dose-dependent apoptosis in PC12 cells: relevance to Parkinson's disease. J Neurochem 63:1987-1990.

Henneberry RC, Novelli A, Cox JA, and Lysko PG (1989) Neurotoxicity at the N-methyl-D-aspartate receptor in energy-compromised neurons: an hypothesis for cell death in aging and disease. Ann NY Acad Sci 568:225-233.

Kilbourn MR, Charalambous A, Frey KA, Sherman P, Higgins DSJ, and Greenamyre JT (1997) Intrastriatal neurotoxin injections reduce in vitro and in vivo binding of radiolabeled rotenoids to mitochondrial complex I. J Cereb Blood Flow Metab 17:265-272.

Jordán J, Galindo MF, and Miller RJ (1997) Role of calpain- and interleukin-1 $\beta$ converting enzyme-like proteases in the $\beta$-amyloid-induced death of rat hippocampal neurons in culture. $J$ Neurochem 68:1612-1621.

Leist M and Nicotera P (1997) Calcium and neural death. Rev Physiol Pharmacol Biochem 132:79-125.

Leist M, Fava E, Montecucco C, and Nicotera P (1997a) Peroxynitrite and NO-donors induce neuronal apoptosis by eliciting autocrine excitotoxicity. Eur J Neurosci 9:1488-1498

Leist M, Single B, Castoldi AF, Kühnle S, and Nicotera P (1997b) Intracellular ATP concentration: a switch deciding between apoptosis and necrosis. J Exp Med 185: $1481-1486$.

Leist M, Single B, Künstle G, Volbracht C, Hentze H, and Nicotera P (1997c) Apoptosis in the absence of poly-(ADP-ribose) polymerase. Biochem Biophys Res Commun 233:518-522.

Leist M, Volbracht C, Kühnle S, Fava E, Ferrando-May E, and Nicotera P (1997d) Caspase-mediated apoptosis in neuronal excitotoxicity triggered by nitric oxide. Mol Med 3:750-764.

Leist M and Nicotera P (1998) Apoptosis, excitotoxicity, and neuropathology. Exp Cell Res 239:183-201. 
Loddick SA, MacKenzie A, and Rothwell NJ (1996) An ICE inhibitor, z-VAD-DCB, attenuates ischaemic brain damage in the rat. Neuroreport 7:1465-1468.

Marini AM, Schwartz JP, and Kopin IJ (1989) The neurotoxicity of 1-methyl-4phenylpyridinium in cultured cerebellar granule cells. J Neurosci 9:3665-3672.

Monyer H, Giffard RG, Hartley DM, Dugan LL, GMP, and Choi DW (1992) Oxygen or glucose deprivation-induced neuronal injury in cortical cell cultures is reduced by tetanus toxin. Neuron 8:967-973.

Nath R, Raser KJ, Stafford D, Hajimohammadreza I, Rosner A, Allen H, Talanian RV, Yuen P, Gilbertsen RB, and Wang KKW (1996) Non-erythroid alpha-spectin breakdown by calpain and interleukin 1 beta-converting-enzyme-like protease(s) in apoptotic cells: contributory roles of both protease families in neuronal apoptosis. Biochem J 319:683-690.

Nicklas WJ, Vyas I, and Heikkila RE (1985) Inhibition of NADH-linked oxidation in brain mitochondria by 1-methyl-4-phenyl-pyridine, a metabolite of the neurotoxin, 1-methyl-4-phenyl-1,2,5,6-tetrahydropyridine. Life Sci 36:2503-2508.

Schousboe A, Meier E, Drejer J, and Hertz L (1989) Preparation of primary cultures of mouse (rat) cerebellar granule cells, in A Dissection and Tissue Culture Manual of the Nervous System (Shahar A, de Vellis J, Vernadakis A, and Haber B, eds) pp 203-206, Alan R. Liss, New York.

Schulz JB, Matthews RT, Muqit MMK, Browne SE, and Beal MF (1995) Inhibition of neuronal nitric oxide synthase by 7 -nitroindazole protects against MPTPinduced neurotoxicity in mice. J Neurochem 64:936-939.

Siman R and Noszek JC (1988) Excitatory amino acids activate calpain I and induce structural protein breakdown in vivo. Neuron 1:279-287.

Srivastava R, Brouillet E, Beal MF, Storey E, and Hyman BT (1993) Blockade of 1-methyl-4-phenylpyridinium ion $\left(\mathrm{MPP}^{+}\right)$nigral toxicity in the rat by prior decortication or MK-801 treatment: a stereological estimate of neuronal loss. Neurobiol Aging 14:295-301.

Stefanis L, Troy CM, Qi H, and Greene LA (1997) Inhibitors of trypsin-like serine proteases inhibit processing of the caspase Nedd-2 and protect PC12 cells and sympathetic neurons from death evoked by withdrawal of trophic support. $\mathrm{J} \mathrm{Neu}$ rochem 69:1425-1437.
Szatkowski M and Attwell D (1994) Triggering and execution of neuronal death in brain ischaemia: two phases of glutamate release by different mechanisms. Trends Neurosci 17:359-365.

Tatton NA and Kish SJ (1997) In situ detection of apoptotic nuclei in the substantia nigra compacta of 1-methyl-4-phenyl-1,2,3,6-tetrahydropyridine-treated transferase labelling and acridine orange staining. Neuroscience 77:1037-1048.

Tipton KF and Singer TP (1993) Advances in our understanding of the mechanisms of the neurotoxicity of MPTP and related compounds. J Neurochem 61:1191-1206.

Turski L, Bressler K, Rettig K-J, Löschmann P-A, and Wachtel H (1991) Protection of substantia nigra from $\mathrm{MPP}^{+}$neurotoxicity by N-methyl-D-aspartate antagonists. Nature (Lond) 349:414-418.

Villa P, Kauffmann SH, and Earnshaw WC (1997) Caspases and caspase inhibitors. Trends Biochem Sci 22:388-393.

Wang Z-Q, Auer B, Stingl L, Berghammer H, Haidacher D, Schweiger M, and Wagner EF (1995) Mice lacking ADPRT and poly(ADP-ribosyl)ation develop normally but are susceptible to skin disease. Genes Dev 9:509-520.

Zeevalk GD and Nicklas WJ (1990) Chemically induced hypoglycemia and anoxia: relationship to glutamate receptor-mediated toxicity in retina. J Pharmacol Exp Ther 253:1285-1292.

Zeevalk GD and Nicklas WJ (1991) Mechanisms underlying initiation of excitotoxicity associated with metabolic inhibition. J Pharmacol Exp Ther 257:870878.

Zhang J, Dawson VL, Dawson TM, and Snyder SH (1994) Nitric oxide activation of poly(ADP-ribose) synthetase in neurotoxicity. Science (Washington DC) 263 : $687-689$.

Send reprint requests to: $\mathrm{Dr} P$. Nicotera, University of Konstanz, Faculty of Biology, Department of Molecular Toxicology, Box X911, D-78457 Konstanz, Germany. E-mail: pierluigi.nicotera@uni-konstanz.de 